ARTICLE

\title{
Allomorphy as a mechanism of post-translational control of enzyme activity
}

\author{
Henry P. Wood ${ }^{1,4}$, F. Aaron Cruz-Navarrete (10) ${ }^{1,4 凶}$, Nicola J. Baxter ${ }^{1,2,4}$, Clare R. Trevitt ${ }^{1}$, Angus J. Robertson ${ }^{1,3}$, \\ Samuel R. Dix (D) ${ }^{1}$, Andrea M. Hounslow', Matthew J. Cliff (iD) ${ }^{2} \&$ Jonathan P. Waltho (1D) 1,2凶
}

Enzyme regulation is vital for metabolic adaptability in living systems. Fine control of enzyme activity is often delivered through post-translational mechanisms, such as allostery or allokairy. $\beta$-phosphoglucomutase ( $\beta$ PGM) from Lactococcus lactis is a phosphoryl transfer enzyme required for complete catabolism of trehalose and maltose, through the isomerisation of $\beta$ glucose 1-phosphate to glucose 6-phosphate via $\beta$-glucose 1,6-bisphosphate. Surprisingly for a gatekeeper of glycolysis, no fine control mechanism of $\beta$ PGM has yet been reported. Herein, we describe allomorphy, a post-translational control mechanism of enzyme activity. In $\beta P G M$, isomerisation of the K145-P146 peptide bond results in the population of two conformers that have different activities owing to repositioning of the K145 sidechain. In vivo phosphorylating agents, such as fructose 1,6-bisphosphate, generate phosphorylated forms of both conformers, leading to a lag phase in activity until the more active phosphorylated conformer dominates. In contrast, the reaction intermediate $\beta$-glucose 1,6-bisphosphate, whose concentration depends on the $\beta$-glucose 1-phosphate concentration, couples the conformational switch and the phosphorylation step, resulting in the rapid generation of the more active phosphorylated conformer. In enabling different behaviours for different allomorphic activators, allomorphy allows an organism to maximise its responsiveness to environmental changes while minimising the diversion of valuable metabolites.

\footnotetext{
${ }^{1}$ Krebs Institute for Biomolecular Research, Department of Molecular Biology and Biotechnology, The University of Sheffield, Sheffield S10 2TN, UK.

${ }^{2}$ Manchester Institute of Biotechnology and School of Chemistry, The University of Manchester, Manchester M1 7DN, UK. ${ }^{3}$ Present address: Laboratory of Chemical Physics, National Institute of Diabetes and Digestive and Kidney Diseases, National Institutes of Health, Bethesda, Maryland 20892, USA. ${ }^{4}$ These authors contributed equally: Henry P. Wood, F. Aaron Cruz-Navarrete, Nicola J. Baxter. ${ }^{凶}$ email: facruznavarrete1@sheffield.ac.uk; j.waltho@sheffield.ac.uk
} 
nzyme regulation is vital in maintaining the balance of catabolism and anabolism in living systems ${ }^{1-3}$. Enzyme activity is subject to precise control, sometimes involving manifold layers of regulation, and failure often results in metabolic disorders and disease ${ }^{4,5}$. Regulatory mechanisms are divided into two broad categories: those relating to the control of enzyme concentration (coarse control) and those that modulate enzyme activity (fine control). In coarse control, concentration is determined by transcriptional modulation of gene expression and the balance between the rates of translation and degradation, with additional contributions from maturation, cellular compartmentalisation and local co-clustering ${ }^{6-9}$. Coarse control occurs on relatively long timescales (hours to days). In fine control, a diverse group of regulatory mechanisms act to modulate enzyme activity over much shorter timescales (<second to minutes). This group includes the binding of regulatory molecules and reversible covalent modification ${ }^{10,11}$, and often involves allosteric modulation, where an effector, acting somewhere other than the active site, stabilises forms of the enzyme with a reduced or enhanced activity $2,12-14$. Alternatively, allokairy is a fine control mechanism, where the activity of a monomeric enzyme is modulated by the near-equivalence of the conformational exchange rate and the catalytic rate in a substrate concentration-dependent manner ${ }^{15,16}$.

Precise enzyme regulation allows organisms to be responsive to environmental changes and to exploit multiple energy sources. Lactococcus lactis (L. lactis) is a Gram-positive bacterium that has worldwide usage in the manufacture of fermented dairy products and in the commercial production of lactic acid ${ }^{17}$. It can grow on a variety of carbohydrate media including trehalose and maltose ${ }^{18-20}$. Trehalose is transported into $L$. lactis by the phosphoenolpyruvate-dependent phosphotransferase system, yielding trehalose 6-phosphate (T6P), which is phosphorolysed by $\mathrm{P}_{\mathrm{i}}$-dependent trehalose 6-phosphate phosphorylase to $\beta$ glucose 1 -phosphate $(\beta \mathrm{G} 1 \mathrm{P})$ and glucose 6 -phosphate $(\mathrm{G} 6 \mathrm{P})^{21}$ (Supplementary Fig. 1). In contrast, maltose enters cells by the ATP-dependent permease system and is phosphorolysed by the action of $\mathrm{P}_{\mathrm{i}}$-dependent maltose phosphorylase to $\beta \mathrm{G} 1 \mathrm{P}$ and glucose $^{22}$. Glucose is subsequently phosphorylated to G6P by glucokinase and enters glycolysis via fructose 1,6-bisphosphate (F16BP). For complete catabolism of both trehalose and maltose, the isomerisation of $\beta \mathrm{G1P}$ to G6P is catalysed by $\beta$ phosphoglucomutase ( $\beta$ PGM, EC 5.4.2.6, $25 \mathrm{kDa}$ ). $\beta$ PGMdeficient $L$. lactis is unable to grow or has impaired growth, when the sole carbon source is trehalose or maltose, respectively ${ }^{23}$. With maltose, $\beta$ G1P accumulates intracellularly and is excreted into the growth medium. Correspondingly, both $\mathrm{P}_{\mathrm{i}^{-}}$ dependent trehalose 6-phosphate phosphorylase and $\mathrm{P}_{\mathrm{i}}$-dependent maltose phosphorylase (Supplementary Fig. 1) operate in the reverse sense to their physiological roles in wild-type L. lactis, resulting in $\beta \mathrm{G} 1 \mathrm{P}$ being combined with G6P to form T6P or polymerised to form amylose $(\alpha(1-4)$-linked glucose units). In trehalose and maltose metabolism, therefore, $\beta$ PGM acts as the gatekeeper to and from glycolysis, and is expected to be subject to tight regulation. In terms of coarse control, transcription of the BPGM gene $(\operatorname{ggmB})$, which is located in the tre operon, is subject to negative transcriptional control by glucose and lactose ${ }^{19}$. When L. lactis switches from metabolising glucose to metabolising maltose (or by implication, trehalose), there is a significant rise in the specific activity of $\beta$ PGM over a period of several hours. However, no fine control mechanism has yet been identified at basal levels of $\beta$ PGM, which would allow the cell to compete more successfully during a transition between carbohydrate sources.

$\beta \mathrm{PGM}$ is a monomeric magnesium-dependent phosphoryl transfer enzyme of the haloacid dehalogenase (HAD) superfamily ${ }^{24-31}$. The active site is located in the cleft between the $\alpha / \beta$ core domain (M1-D15, S88-K216) and the $\alpha$-helical cap domain (T16-V87), with closure of the cleft through domain reorientation occurring during catalysis. Two phosphate group binding sites are present, a proximal site adjacent to the carboxylate nucleophile and the catalytic $\mathrm{Mg}^{2+}$ ion, and a distal site located $\sim 8 \AA$ away in the closed enzyme ${ }^{29}$. During steady-state catalysis, $\beta$ G1P binds to phosphorylated $\beta$ PGM $\left(\beta \mathrm{PGM}^{\mathrm{P}}\right.$, phosphorylated on D8) and forms $\beta$-glucose 1,6-bisphosphate ( $\beta \mathrm{G} 16 \mathrm{BP})$. Release to solution and subsequent rebinding of $\beta \mathrm{G} 16 \mathrm{BP}$ in the alternate orientation $^{32}$ leads to the formation of G6P and the regeneration of $\beta_{P G M}{ }^{\mathrm{P}}$ (Fig. 1). In vitro, a phosphorylating (priming) agent is required to initiate the catalytic cycle since the half-life of $\beta \mathrm{PGM}^{\mathrm{P}}$ is $\sim 30 \mathrm{~s}^{28}$. In vivo, potential candidates for this agent include F16BP, $\beta$ G1P, G6P, $\alpha$-glucose 1,6-bisphosphate (aG16BP) and acetyl phosphate (AcP), as well as the reaction intermediate, $\beta$ G16BP. However, only $\beta$ G16BP allows $\beta$ PGM to reach its maximum catalytic rate, and a significant lag phase is observed in the reaction with $a \mathrm{G} 16 \mathrm{BP}$ as the phosphorylating agent ${ }^{28}$, until the $\beta \mathrm{G} 16 \mathrm{BP}$ concentration greatly exceeds its resting concentration in the cell. In the current kinetic model for $\beta P G M$ catalysis, $\alpha$ G16BP is also required to act as a very strong inhibitor of $\beta$ PGM. $\alpha$ G16BP is a close structural analogue of $\beta \mathrm{G} 16 \mathrm{BP}^{25}$, but very similar kinetic behaviour is observed when $\mathrm{AcP}$ is used as the phosphorylating agent ${ }^{31}$, suggesting that other factors are con-

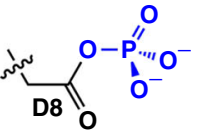<smiles>O=P([O-])(O)OC1O[C@H](CO)[C@@H](O)[C@H](O)[C@H]1O</smiles>
$\beta P G M^{P}: \beta G 1 P$<smiles>CC(C)(C)C(=O)OP(=O)([O-])[O-]</smiles>

$\beta P G M^{P}: \beta G 6 P$<smiles>O=P([O-])([O-])OCC1OC(O)C(O)C(O)C1O</smiles><smiles>C=C=C</smiles>

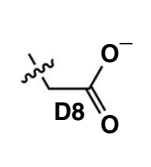<smiles>O=P([O-])([O-])OC[C@H]1O[C@H](OP(=O)([O-])O)[C@@H](O)[C@H](O)[C@H]1O</smiles>

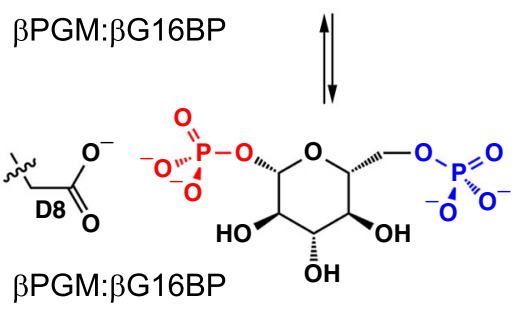

Fig. 1 PPGM catalytic cycle. $\beta$ PGM reaction scheme for the enzymatic conversion of $\beta$ G1P to G6P via a $\beta$ G16BP intermediate. The phosphoryl transfer reaction between phospho-enzyme ( $\beta P G M P$, phosphorylated at residue $D 8$ ) and $\beta G 1 P$ is illustrated with the transferring phosphate (blue) in the proximal site and the 1-phosphate (red) of $\beta$ G1P in the distal site. The phosphoryl transfer reaction between $\beta$ PGM and $\beta$ G16BP is shown with the transferring phosphate (red) in the proximal site and the 6-phosphate (blue) of $\beta \mathrm{G} 16 \mathrm{BP}$ in the distal site. 

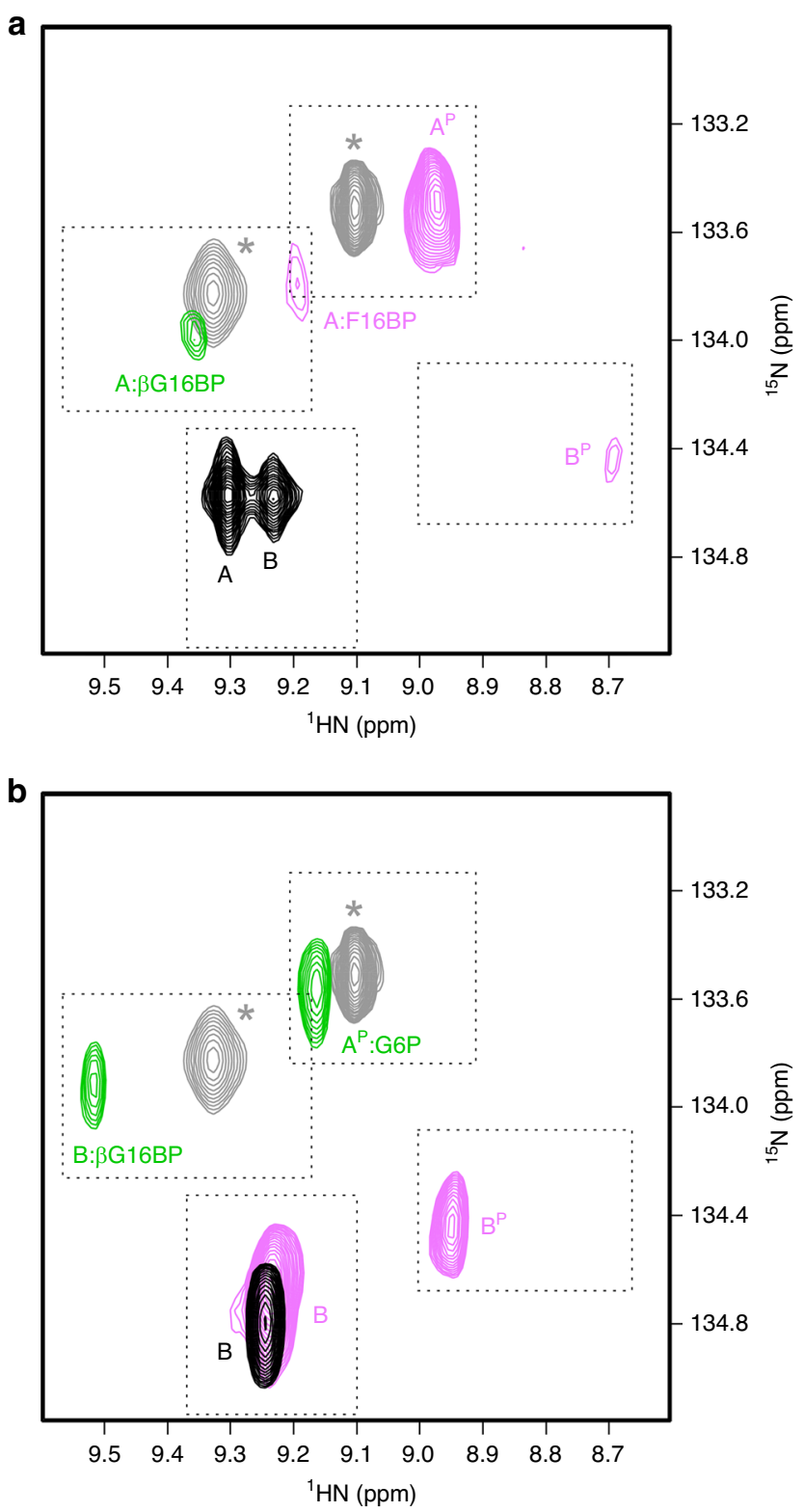

Fig. 2 Effect of different phosphorylating agents on $\beta$ PGM. $\mathbf{a}, \mathbf{b}$ Overlays of a section of ${ }^{1} \mathrm{H}^{15} \mathrm{~N}$-TROSY spectra highlighting the behaviour of residue A113. a $\beta P G M_{W T}$ (black) populates conformer $A$ and conformer $B$ in slow exchange. $\beta P G M_{W T}$ supplemented with F16BP (pink) populates phosphorylated conformer $A\left(A^{P}\right)$ as the dominant species, phosphorylated conformer $B\left(B^{P}\right)$ and a $\beta P G M_{W T}: F 16 B P$ species (A:F16BP). $\beta P G M_{W T}$ supplemented with $\beta$ G16BP (green) populates an $A: \beta G 16 B P$ complex. b $\beta P G M_{P 146 A}$ (black) populates one conformer (conformer B). $\beta P G M_{P 146 A}$ supplemented with F16BP (pink) populates conformer $B$ and $B^{P}$. $\beta P G M_{P 146 A}$ supplemented with $\beta G 16 B P$ (green) populates a $A^{P}: G 6 P$ complex and a $\mathrm{B}: \beta \mathrm{G} 16 \mathrm{BP}$ complex. Peaks indicated by grey asterisks correspond to the $\beta P G M_{W T}: B F_{3}$ complex (grey; $\delta_{N}=133.5$ ppm; $B M R B ~ 17851^{35}$ ), which is an analogue of $A^{P}$, and the $\mathrm{Mg}^{2+}$-saturated $\beta P G M_{D 10 N}: \beta G 16 B P$ complex (grey; $\delta_{N}=133.8$ ppm; BMRB 2717431), which is a mimic of the $A: \beta G 16 B P$ complex, and are shown for comparison.

tributing to post-translational control of $\beta$ PGM. Here we show, through combined use of NMR spectroscopy, X-ray crystallography, site-directed mutagenesis and kinetic assays, that a regulatory mechanism is operating in $\beta$ PGM, which we have termed allomorphy to illustrate its relationship to and distinction from allostery and allokairy. In the substrate-free enzyme, the isomerisation of proline 146 results in the near-equal population of two conformers that have different activities. Alternative phosphorylating agents such as $\mathrm{F} 16 \mathrm{BP}$ and AcP generate phosphorylated forms of both conformers, resulting in a lag phase in $\beta$ PGM activity until the more active phosphorylated conformer dominates. In contrast, the $\beta \mathrm{G} 16 \mathrm{BP}$ reaction intermediate is able to couple the conformational switch and the phosphorylation step, resulting in the rapid generation of the more active phosphorylated species. This allows the $\beta \mathrm{G} 16 \mathrm{BP}$ concentration to effectively act as a surrogate of the $\beta$ G1P concentration and modulate the activity of $\beta$ PGM according to the carbohydrate source available to $L$. lactis.

\section{Results}

$\beta$ PGM ${ }_{\mathrm{WT}}$ exchanges slowly between two stable conformations. The observation of a lag phase when using either aG16BP or $\mathrm{AcP}^{28,31}$ as the phosphorylating agent implies that the target of phosphorylation, the substrate-free enzyme, has a role in posttranslational control. Hence, the solution properties of substratefree wild-type $\beta \mathrm{PGM}\left(\beta \mathrm{PGM}_{\mathrm{WT}}\right)$ were investigated using NMR spectroscopy. In the previous backbone resonance assignment of $\beta \mathrm{PGM}_{\mathrm{WT}}$ (BMRB $7235^{26}$ ) performed in standard NMR buffer (50 $\mathrm{mM} \mathrm{K}^{+}$HEPES (pH 7.2), $5 \mathrm{mM} \mathrm{MgCl}_{2}, 2 \mathrm{mM} \mathrm{NaN}_{3}, 10 \%$ (v/ v) ${ }^{2} \mathrm{H}_{2} \mathrm{O}$ and $1 \mathrm{mM}$ trimethylsilyl propanoic acid (TSP)) containing $10 \mathrm{mM} \mathrm{NH}_{4} \mathrm{~F}$, two features were apparent during the analysis: (1) peaks of 30 active site residues were missing from the spectra owing to line-broadening resulting from conformational exchange on the millisecond timescale and (2) a large number of unassigned ${ }^{1} \mathrm{H}_{\mathrm{N}},{ }^{15} \mathrm{~N},{ }^{13} \mathrm{C} \alpha,{ }^{13} \mathrm{C} \beta$ and ${ }^{13} \mathrm{C}$ ' resonances were present with a low intensity. To test whether HEPES or $\mathrm{NH}_{4} \mathrm{~F}$ were contributing to the millisecond conformational exchange, spectra were recorded in tris buffer ( $50 \mathrm{mM}$ tris ( $\mathrm{pH} 7.2), 5 \mathrm{mM} \mathrm{MgCl}_{2}, 2$ $\mathrm{mM} \mathrm{NaN}, 10 \%(\mathrm{v} / \mathrm{v}){ }^{2} \mathrm{H}_{2} \mathrm{O}$ and $1 \mathrm{mM}$ TSP) and mixtures of HEPES and tris buffers in order to transfer the assignment between conditions ${ }^{33}$. It was noticed that the inclusion of $5 \mathrm{mM}$ tris in the standard NMR buffer increased the intensity of the unassigned resonances significantly and therefore all observable resonances in the spectra were re-assigned using standard triple resonance TROSY-based methodology ${ }^{34}$. Excluding the ten proline residues and the $\mathrm{N}$-terminal methionine, the backbone resonances of 193 out of a total of 210 residues (92\%) were assigned. Seventeen residues located in the vicinity of the active site remained unassigned (L9, D10, G11, R38, L44, K45, G46, S48, R49, E50, D51, S52, L53, K117, N118, D170 and S171). Notably, 102 of the assigned residues displayed pairs of resonances in the ${ }^{1} \mathrm{H}^{15} \mathrm{~N}$-TROSY spectrum (Fig. 2a, Supplementary Fig. 2a), consistent with the population of two $\beta \mathrm{PGM}_{\mathrm{WT}}$ conformers $(70 \%$ conformer A, BMRB 28095 and 30\% conformer B, BMRB 28096). A further five residues (K145, A147, D149, I150 and Q176) have assignments in conformer $\mathrm{A}$, but are missing assignments in conformer $\mathrm{B}$, owing to some differential millisecond conformational exchange occurring in the two species. The $\beta \mathrm{PGM}_{\mathrm{WT}}$ conformers are present in the spectra as a result of slow conformational exchange rather than as chemically distinct species, as the addition of $3 \mathrm{mM} \mathrm{BeCl}_{2}$ and $10 \mathrm{mM} \mathrm{NH}_{4} \mathrm{~F}$ to the $\beta \mathrm{PGM}_{\mathrm{WT}}$

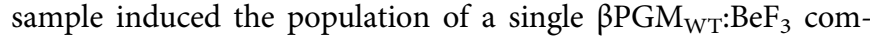
plex (an analogue of phosphorylated conformer A; BMRB $17851^{35}$ ) (Supplementary Fig. 3a). The exchange between conformer A and conformer B is on the multi-second timescale, with $k_{\mathrm{ex}} \leq 1.0 \mathrm{~s}^{-1}$ from ZZ-exchange measurements. Differences in chemical shift between the two conformers (Supplementary Fig. 4a) indicate that the regions of $\beta \mathrm{PGM}_{\mathrm{WT}}$ involved in the multi-second conformational exchange process are located primarily in the core domain and comprise the D137-A147 loop, the $\beta$-strands (K109-A113 and D133-A136) at the outer edge of the 


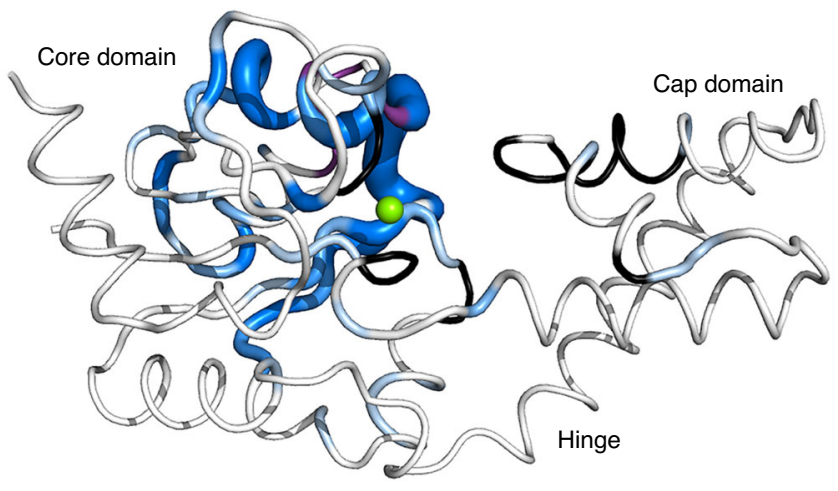

Fig. 3 Exchange behaviour in $\boldsymbol{\beta P G} \mathbf{M}_{\mathbf{W T}}$. Crystal structure of $\beta$ PGM $\mathrm{WT}_{\mathrm{T}}$ (PDB $2 \mathrm{WHE}^{29}$ ) showing residues of $\beta P G M_{W T}$ undergoing conformational exchange on different timescales. Residues that populate two conformations in slow exchange are coloured in shades of blue according to chemical shift differences between conformer $A$ and conformer $B$, with the intensity of colour and thickness of the backbone corresponding to larger values. Residues in conformer $A$ and conformer $B$ with missing backbone amide peaks in the ${ }^{1} \mathrm{H}^{15} \mathrm{~N}$-TROSY spectrum of $\beta P G M_{W T}$ are coloured black, whereas missing backbone amide peaks in conformer B only are coloured purple. The amide ${ }^{1} \mathrm{H}^{15} \mathrm{~N}$ coherences are likely broadened beyond detection owing to intermediate exchange on the millisecond timescale. The catalytic $\mathrm{Mg}^{2+}$ ion is indicated as a green sphere.

$\beta$-sheet and the I152-S163 and Q172-A183 $\alpha$ - and 310 -helical regions (Fig. 3). Predicted random coil index order parameters $\left(\mathrm{RCI}-\mathrm{S}^{2}\right)^{36}$ show a decrease in value for conformer $\mathrm{B}$ in two regions (G32-R38 in the cap domain and D133-K145 in the core domain) (Supplementary Fig. 5a), which indicates increased conformational flexibility compared with conformer A.

Influence of physiological factors on the conformational exchange. An investigation of factors that could potentially affect the population distribution of conformer $\mathrm{A}$ and conformer $\mathrm{B}$ was performed using ${ }^{1} \mathrm{H}^{15} \mathrm{~N}$-TROSY spectra of $\beta \mathrm{PGM}_{\mathrm{WT}}$ recorded under different conditions of temperature, $\mathrm{pH}$, hydrostatic pressure, $\mathrm{MgCl}_{2}(0-100 \mathrm{mM}), \mathrm{NaCl}(0-200 \mathrm{mM}), \mathrm{K}^{+}$HEPES buffer $(0-200 \mathrm{mM})$ and $\beta \mathrm{PGM}_{\mathrm{WT}}$ concentration $(0.1-1.2 \mathrm{mM})$. All of these perturbations had little or no effect, apart from the addition of either $\mathrm{MgCl}_{2}(100 \mathrm{mM})$ or $\mathrm{NaCl}(200 \mathrm{mM})$ to standard NMR buffer, which shifted the population of $\beta \mathrm{PGM}_{\mathrm{WT}}$ primarily to conformer A (Supplementary Fig. 6a-d). Buffer exchange into deionised water resulted in conformer $\mathrm{B}$ being the dominant population. However, both conformer $\mathrm{A}$ and conformer $\mathrm{B}$ remained populated when $\mathrm{Mg}^{2+}$ was removed from the NMR buffer solution, showing that the multi-second conformational exchange is not simply a result of incomplete saturation of the catalytic $\mathrm{Mg}^{2+}$-binding site. These observations indicate that chloride anions perturb the population distribution.

The inorganic ionic composition of $L$. lactis cytoplasm $(\sim 2 \mathrm{mM}$ $\left.\mathrm{Mg}^{2+}, \sim 50 \mathrm{mM} \mathrm{Na}{ }^{+}, \sim 400 \mathrm{mMK}^{+}, \sim 50 \mathrm{mM} \mathrm{Cl}^{-}\right)^{37}$ overlaps with the concentration ranges tested, where the population distribution between conformer $\mathrm{A}$ and conformer $\mathrm{B}$ remained unaffected. Therefore, it is expected that both conformer A and conformer B are populated in cytoplasm. However, the intracellular milieu is a complex mix of metabolites that could influence this equilibrium. This environment was mimicked through the use of bovine skimmed milk, a medium in which $L$. lactis thrives within the dairy industry. It is anticipated that the organic components in milk will also be present in cytoplasm. Moreover, the inorganic ionic composition $\left(\sim 5 \mathrm{mM} \mathrm{Mg}^{2+}, \sim 24\right.$ $\left.\mathrm{mM} \mathrm{Na}^{+}, \sim 38 \mathrm{mM} \mathrm{K}^{+}, \sim 28 \mathrm{mM} \mathrm{Cl}^{-}\right)^{38}$ is similar to cytoplasm (except for $\mathrm{K}^{+}$, which has no effect on the equilibrium between conformer A and conformer B), so any effects will be owing to the influence of metabolites. $\beta$ PGM $_{\mathrm{WT}}$ was diluted fivefold into fresh skimmed milk, which had been filtered to remove species with a molecular weight larger than $10 \mathrm{kDa}$. The ${ }^{1} \mathrm{H}^{15} \mathrm{~N}-\mathrm{TROSY}$ spectrum revealed that both conformer $\mathrm{A}$ and conformer $\mathrm{B}$ were populated with a similar ratio $(60 \%$ conformer $\mathrm{A}$ and $40 \%$ conformer $B$ ) to $\beta \mathrm{PGM}_{\mathrm{WT}}$ recorded in standard NMR buffer (Supplementary Figs. 2c, 7a). However, minor chemical shift changes in the active site loops and the sharpening of some peaks that were line-broadened under standard conditions indicated that one of the milk components was binding in the vicinity of the active site. The two dominant organic components of the filtered milk were lactose and citrate (Supplementary Fig. 2d). Titration of lactose into $\beta \mathrm{PGM}_{\mathrm{WT}}$ had no effect on the ${ }^{1} \mathrm{H}^{15} \mathrm{~N}$-TROSY spectrum, whereas titration of citrate led to equivalent chemical shift changes and sharpening of line-broadened peaks to those observed in milk. Similar effects were observed in both conformer $A$ and conformer B. Hence, $\beta P_{\text {GMT }}$ was crystallised in the presence of citrate and the structure was determined to $2.1 \AA$ resolution (PDB 6YDM; Supplementary Fig. 8a-c, Supplementary Table 1). Two chains are present in the crystallographic asymmetric unit, one of which has citrate and acetate bound, whilst the other has tris and acetate bound. Citrate is coordinated in the active site by residues T16, H20, V47-R49 and A115-K117 and mimics substrate binding to some extent. Both monomers share a similar fold and overlay closely with a previously reported substrate-free $\beta \mathrm{PGM}_{\mathrm{WT}}$ structure (PDB $2 \mathrm{WHE}^{29}$; non-H atom RMSDs of $0.56 \AA$ and $0.95 \AA$ ). Although only one of the two conformers observed in solution is represented in the crystal, the NMR experiments show that both conformer A and conformer B remain well-populated under physiological conditions.

The conformational exchange involves cis-trans proline isomerisation. Exchange phenomena on multi-second timescales in proteins are often a consequence of cis-trans isomerisation of Xaa-Pro peptide bonds ${ }^{39,40}$. The largest differences in chemical shift between conformer A and conformer B are observed for residues in a loop (D137-A147) containing two proline residues (P138 and P146) (Supplementary Fig. 4a). From the crystal structures of the substrate-free form of the enzyme (PDB 6YDL (Supplementary Table 1) determined to $1.5 \AA$ resolution, which compares closely with $\mathrm{PDB} 2 \mathrm{WHE}^{29}$ (non-H atom $\mathrm{RMSD}=0.53$ $\AA$ ) and PDB $1 \mathrm{ZOL}^{25}$ (non-H atom $\mathrm{RMSD}=0.65 \AA$ )), nine trans Xaa-Pro peptide bonds are present in $\beta \mathrm{PGM}_{\mathrm{WT}}$, whereas the K145-P146 peptide bond adopts a cis conformation. Proline residues with cis peptide bonds have ${ }^{13} \mathrm{C} \beta$ nuclei that resonate 2.0-2.5 ppm downfield from those with trans peptide bonds ${ }^{41}$ and therefore the isomerisation state of the Xaa-Pro peptide bonds for $\beta \mathrm{PGM}_{\mathrm{WT}}$ in solution was investigated. All but one of the assigned proline residues in conformer $\mathrm{A}$ and conformer $\mathrm{B}$ possess ${ }^{13} \mathrm{C} \beta$ chemical shifts in the range $30.4-31.9 \mathrm{ppm}$ consistent with the population of trans Xaa-Pro peptide bonds (Supplementary Fig. 5b). In contrast, the ${ }^{13} \mathrm{C} \beta$ chemical shift for P146 (34.7 ppm) corroborates the presence of a cis K145-P146 peptide bond in solution for conformer A. However for conformer $\mathrm{B}$, the absence of proline ${ }^{13} \mathrm{C} \beta$ resonances for P146 and P148, owing to millisecond conformational exchange in the K145-I150 region, precluded an identification of the isomerisation state for these proline residues using NMR methods.

To explore whether proline isomerisation at the K145-P146 peptide bond is the source of the multi-second conformational exchange in $\beta \mathrm{PGM}_{\mathrm{WT}}$, the $\beta$ PGM variant P146A $\left(\beta \mathrm{PGM}_{\mathrm{P} 146 \mathrm{~A}}\right)$ was prepared and the solution properties of the substrate-free form were investigated. A ${ }^{1} \mathrm{H}^{15} \mathrm{~N}$-TROSY spectrum shows that only a single species is present (Fig. 2b, Supplementary Fig. 2b) 

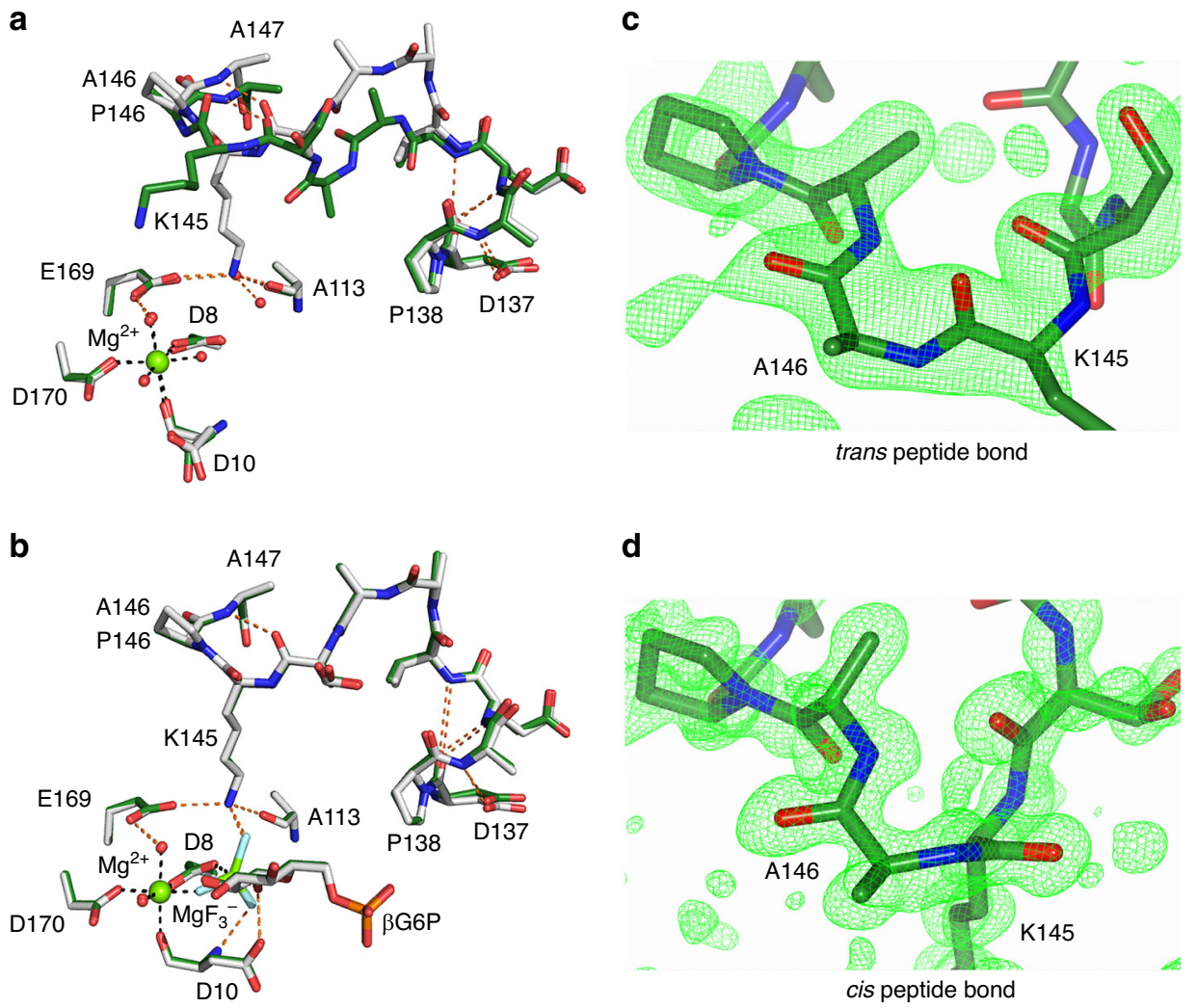

Fig. 4 Conformational plasticity of the active site of $\boldsymbol{\beta P G M}$. $\mathbf{a}$, $\mathbf{b}$ Active sites of $\beta P G M_{W T}$ (as conformer $A$ ) and $\beta P G M P 146 A$ superposed on the core domain. a Selected residues are shown as sticks for the crystal structures of $\beta P G M_{W T}$ (grey carbon atoms; PDB 6YDL) and $\beta P G M P 146 A$ (dark green carbon

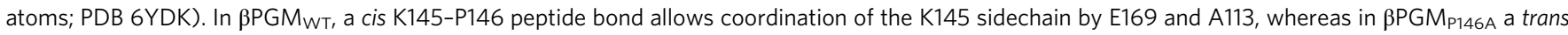
K146-A146 peptide bond changes significantly the backbone conformation of the D137-A147 loop, which precludes active site engagement of the K145 sidechain. The catalytic $\mathrm{Mg}^{2+}$ ion is drawn as a green sphere, black dashes indicate metal ion coordination and orange dashes show probable hydrogen bonds. $\mathbf{b}$ Selected residues, the $\mathrm{MgF}_{3}{ }^{-}$moiety and G6P are shown as sticks for the crystal structures of the $\beta P G M \mathrm{WT}_{\mathrm{T}}: \mathrm{MgF}_{3}$ :G6P TSA complex (grey carbon atoms; PDB $2 \mathrm{WF}^{29}$ ) and the $\beta P \mathrm{PG}_{\mathrm{P} 146 \mathrm{~A}}: \mathrm{MgF}_{3}: \mathrm{G} 6 \mathrm{P}$ TSA complex (dark green carbon atoms; PDB 6YDJ). $\beta P G M_{\mathrm{WT}}$ maintains the cis K145-P146 peptide bond, whereas $\beta P G M_{P 146 A}$ changes the isomerisation state of the K145-A146 peptide bond from a trans conformation in the substratefree enzyme to a cis conformation in the transition state. c, d Omit maps generated by refinement in the absence of residues S144-P148 in $\beta$ PGM $146 \mathrm{~A}$. c The S144-P148 segment, containing a trans K145-A146 peptide bond, with positive difference density (Fo-Fc; green mesh contoured at $+2.5 \sigma)$ in substrate-free $\beta$ PGMP146A. d The S144-P148 segment, containing a cis K145-A146 peptide bond, with positive difference density (Fo-Fc; green mesh contoured at $+2.5 \sigma)$ in the $\beta P G M M_{146 A}: M_{g F}: G 6 P$ TSA complex.

and 194 out of a total of 211 residues (92\%) were assigned using standard TROSY-based methodology (BMRB 2792042). The same seventeen residues as $\beta \mathrm{PGM}_{\mathrm{WT}}$ remain unassigned owing to millisecond conformational exchange. The chemical shifts of $\beta \mathrm{PGM}_{\mathrm{P} 146 \mathrm{~A}}$ were compared with those of conformer $\mathrm{A}$ and conformer B of $\beta \mathrm{PGM}_{\mathrm{WT}}$ (Supplementary Fig. $4 \mathrm{~b}, \mathrm{c}$ ). Although the largest perturbations relate to the mutation site (together with an associated propagation of effects through the P148-V158 and S171-G182 a-helices), additional significant and widespread chemical shift differences are present between conformer A and $\beta \mathrm{PGM}_{\mathrm{P} 146 \mathrm{~A}}$, especially in the D137-A147 loop. In contrast, much smaller chemical shift changes are observed between conformer B and $\beta \mathrm{PGM}_{\mathrm{P} 146 \mathrm{~A}}$, indicating that the solution conformations for these species are closely similar. However, although the K145-A146 peptide bond in $\beta \mathrm{PGM}_{\mathrm{P} 146 \mathrm{~A}}$ is likely to adopt a trans conformation as the dominant population, the isomerisation state remains ambiguous using NMR methods. Therefore, $\beta \mathrm{PGM}_{\mathrm{P} 146 \mathrm{~A}}$ was crystallised and the structure was determined to 2.0 A resolution (PDB 6YDK; Supplementary Table 1). The cap and the core domains of the crystal structure superimpose closely with those of $\beta \mathrm{PGM}_{\mathrm{WT}}$ (non-H atom RMSD $=0.33 \AA$, PDB $2 \mathrm{WHE}^{29}$; non-H atom RMSD $=0.48 \AA$, PDB 6YDL; non-H atom $\mathrm{RMSD}=0.51 \AA$, PDB $1 \mathrm{ZOL}^{25}$ ). The D137-A147 loop exhibits elevated temperature factors, consistent with the lower predicted RCI-S $S^{2}$ values derived from NMR chemical shifts (Supplementary Fig. 5c). The electron density is best fit by the trans conformation of the K145-A146 peptide bond ( $\omega$ dihedral angle $=-177^{\circ}$ ) (Fig. 4a, c). In comparison with $\beta \mathrm{PGM}_{\mathrm{WT}}$, the D137-A147 loop adopts a different conformation, although both a 310 -helix (D137-V141) and a $\beta$-turn hydrogen bond $\left(\mathrm{A}_{147_{\mathrm{HN}}}-\mathrm{S} 144_{\mathrm{CO}}\right)$ are retained. These perturbations in structure are consistent with the chemical shift changes observed between conformer $\mathrm{A}$ and $\beta \mathrm{PGM}_{\mathrm{P} 146 \mathrm{~A}}$ and support the $\beta \mathrm{PGM}_{\mathrm{P} 146 \mathrm{~A}}$ structure being a close model of conformer B.

The most pronounced consequence of the change in isomerisation state of the K145-A146 peptide bond is the failure of the K145 sidechain in $\beta \mathrm{PGM}_{\mathrm{P} 146 \mathrm{~A}}$ to engage in the active site (Fig. 4a). Instead, this sidechain is positioned in the open cleft between the cap and core domains, and is exposed to solvent. In $\beta \mathrm{PGM}_{\mathrm{WT}}$, the $\varepsilon$-amino group of K145 is coordinated by the carbonyl oxygen atom of A113, the carboxylate sidechain of E169, and a water molecule that is replaced in the transition state analogue (TSA) complex (PDB $2 \mathrm{WF}^{29}$ ) by a fluoride ion that mimics an oxygen atom of the transferring phosphoryl group. An electrostatic relationship also exists between the $\varepsilon$-amino group and the carboxylate group of D8. In $\beta \mathrm{PGM}_{\mathrm{P} 146 \mathrm{~A}}$, 

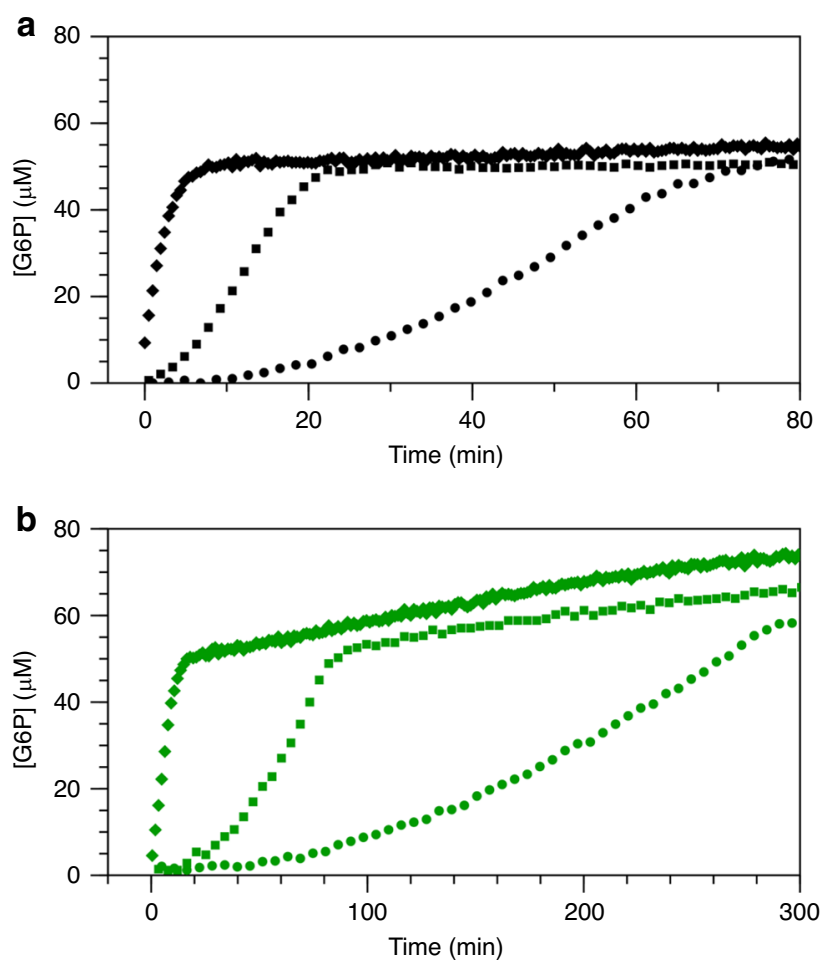

Fig. 5 Kinetic profiles of $\boldsymbol{\beta P G M}$ activity. $\mathbf{a}$, $\mathbf{b}$ Reaction kinetics for the conversion of $\beta$ G1P to G6P catalysed by $\beta$ PGM $M_{W T}$ and $\beta P G M_{P 146 A}$. The rate of G6P production was measured indirectly using a glucose 6-phosphate dehydrogenase coupled assay, in which G6P is oxidised and concomitant $\mathrm{NAD}^{+}$reduction is monitored by the increase in absorbance at $340 \mathrm{~nm}$. Reaction catalysed by either $\mathbf{a} \beta P G M_{W T}$ or $\mathbf{b} \beta P G M_{P 146 A}$ in standard kinetic buffer using either F16BP (circles), AcP (squares) or $\beta$ G16BP (diamonds) as a phosphorylating agent. For clarity, between 100 and $8 \%$ of the data points are included in the kinetic profiles. Following $\beta$ G1P substrate depletion, the kinetic profiles show an apparent increase in G6P concentration, which results from: (1) the concentration of the reaction ingredients through evaporation from the assay plate wells and (2) for the reactions recorded using $\beta$ G16BP, the enzyme-dependent conversion of remaining $\beta$ G16BP to $G 6 P$ via $\beta P G M P$, occurring at a rate proportional to the amount of enzyme.

the position of the missing $\varepsilon$-amino group of K145 and its $\beta \mathrm{PGM}_{\mathrm{WT}}$ hydrogen bonding are satisfied by a water molecule. The predicted RCI-S ${ }^{2}$ order parameters for $\beta P_{\text {PG }} \mathrm{P}_{146 \mathrm{~A}}$ and $\beta$ PGM $_{\mathrm{WT}}$ (Supplementary Fig. 5a, c) share similar profiles apart from the D137-A147 loop region, where the RCI-S ${ }^{2}$ values for $\beta \mathrm{PGM}_{\mathrm{P} 146 \mathrm{~A}}$ indicate increased dynamic properties that broadly mirror those of conformer $\mathrm{B}$ in $\beta \mathrm{PGM}_{\mathrm{WT}}$. Together, these data reveal that $\beta \mathrm{PGM}_{\mathrm{P} 146 \mathrm{~A}}$ reflects the properties of conformer $\mathrm{B}$, and link the chemical shift and RCI-S ${ }^{2}$ differences between conformers to the isomerisation state of the K145-X146 peptide bond. Thus, the multi-second exchange between conformer A and conformer B in solution involves cis-trans proline isomerisation of the K145-P146 peptide bond.

$\beta \mathrm{PGM}_{\mathrm{WT}}$ lag phase depends on the phosphorylating agent. To ensure that the extent of the lag phase observed previously with AcP is not a method dependent observation ${ }^{31}$, the effect of different phosphorylating agents on the mutase activity of $\beta P_{\mathrm{WT}}$ was investigated by monitoring the conversion of $50 \mu \mathrm{M} \beta \mathrm{G} 1 \mathrm{P}$ to G6P with either F16BP $(1 \mathrm{mM})$, AcP $(8 \mathrm{mM})$ or $\beta$ G16BP $(10 \mu \mathrm{M})$ present as phosphorylating agents, using the standard glucose 6phosphate dehydrogenase coupled assay ${ }^{28}$. Despite the crucial involvement of $\beta \mathrm{G} 16 \mathrm{BP}$ as the reaction intermediate in the catalytic cycle, its concentration in the cell can vary markedly and is dependent upon the concentration of $\beta \mathrm{G} 1 \mathrm{P}$. Therefore, F16BP is the most likely phosphorylating agent of $\beta \mathrm{PGM}_{\mathrm{WT}}$ in vivo when L. lactis is growing on glucose-rich media $(\sim 50 \mathrm{mM}$ F16BP ${ }^{17}$ versus $\left.K_{\mathrm{m}} \sim 100 \mu \mathrm{M}^{25}\right)$. AcP is also a potential activator in vivo, as although it is present at lower concentrations $(1-3 \mathrm{mM}$ in Escherichia coli $(E \text {. coli })^{43,44}$ versus $\left.K_{\mathrm{m}} \sim 800 \mu \mathrm{M}^{25}\right)$, it is inherently a much faster phosphorylating agent. In the coupled assay experiments with $\beta \mathrm{PGM}_{\mathrm{WT}}$ (Fig. 5a), when either F16BP or $\mathrm{AcP}$ was used as the phosphorylating agent, their progression curves display significant lag phases. The lag is considerably more pronounced in the F16BP experiment, and consequently the maximum rate of $\beta$ G1P to G6P conversion is not achieved before the substrate is exhausted. When $\beta$ G16BP was used as the phosphorylating agent the kinetic profile shows a linear, fast initial rate. Consequently, initial rate measurements were made at several $\beta$ G1P and $\beta$ G16BP concentrations $(10-700 \mu \mathrm{M}$ and $0.4-100 \mu \mathrm{M}$, respectively) and were globally fitted to an equation derived for a ping-pong mechanism with $\beta \mathrm{G} 1 \mathrm{P}$ inhibition ${ }^{28}$. Accurate fits were obtained at $\beta$ G16BP concentrations up to 10 $\mu \mathrm{M}$, as above this concentration the model no longer describes the data. At elevated $\beta \mathrm{G} 16 \mathrm{BP}$ concentrations, the back reaction from $\beta \mathrm{G} 16 \mathrm{BP}$ to $\beta \mathrm{G} 1 \mathrm{P}$ becomes significant, and the free $\beta \mathrm{G} 16 \mathrm{BP}$ concentration is attenuated owing to a multimeric interaction between $\beta \mathrm{G} 16 \mathrm{BP}$ and $\mathrm{Mg}^{2+}$ ions ${ }^{31}$. Accordingly, the data above $10 \mu \mathrm{M} \beta \mathrm{G} 16 \mathrm{BP}$ were omitted from the fitting. This analysis yielded values for $k_{\text {cat }}$ of $382 \pm 12 \mathrm{~s}^{-1}, K_{\mathrm{m}}(\beta \mathrm{G} 1 \mathrm{P})$ of $91 \pm 4 \mu \mathrm{M}$, $K_{\mathrm{m}}(\beta \mathrm{G} 16 \mathrm{BP})$ of $8.5 \pm 0.3 \mu \mathrm{M}$ and $K_{\mathrm{i}}(\beta \mathrm{G} 1 \mathrm{P})$ of $1510 \pm 100 \mu \mathrm{M}$ (Supplementary Fig. 9a). These values are all higher than those previously reported ${ }^{25,28}$ for $\beta \mathrm{PGM}_{\mathrm{WT}}$ owing to the extension of the analysis to higher $\beta \mathrm{G} 1 \mathrm{P}$ and $\mathrm{Mg}^{2+}$ concentrations.

BPGM catalysis utilises a cis K145-X146 peptide bond. To assess whether $\beta P G M$ is active as conformer $B$, the effect of different phosphorylating agents on the mutase activity of $\beta \mathrm{PGM}_{\mathrm{P} 146 \mathrm{~A}}$ was investigated by monitoring the conversion of 50 $\mu \mathrm{M} \beta \mathrm{G} 1 \mathrm{P}$ to G6P with either F16BP $(1 \mathrm{mM})$, AcP $(8 \mathrm{mM})$ or $\beta \mathrm{G} 16 \mathrm{BP}(10 \mu \mathrm{M})$ present as phosphorylating agents using the standard glucose 6-phosphate dehydrogenase coupled assay. As for $\beta P G M_{W T}$, the kinetic profiles for $\beta P M_{P 146 A}$ display significant lag phases with $\mathrm{F} 16 \mathrm{BP}$ and $\mathrm{AcP}$, whereas the progression curve with $\beta$ G16BP shows a linear, fast initial rate (Fig. 5b). Consequently, initial rate measurements were made at several $\beta$ G1P and $\beta$ G16BP concentrations $(5-500 \mu \mathrm{M}$ and $2-100 \mu \mathrm{M}$, respectively) and were globally fit to the equation used for $\beta \mathrm{PGM}_{\mathrm{WT}}$ above. For $\beta$ PGM $\mathrm{P}_{\mathrm{P} 146 \mathrm{~A}}$, the fitting yielded values for $k_{\mathrm{cat}}$ of $19.2 \pm 0.2 \mathrm{~s}^{-1}, K_{\mathrm{m}}(\beta \mathrm{G} 1 \mathrm{P})$ of $157 \pm 3 \mu \mathrm{M}, K_{\mathrm{m}}(\beta \mathrm{G} 16 \mathrm{BP})$ of 175 $\pm 3 \mu \mathrm{M}$ and $K_{\mathrm{i}}(\beta \mathrm{G} 1 \mathrm{P})$ of $933 \pm 32 \mu \mathrm{M}$ (Supplementary Fig. $\left.9 \mathrm{~b}\right)$. In addition, the equilibration of $\beta$ G1P and G6P for both $\beta P_{G M T}$ and $\beta \mathrm{PGM}_{\mathrm{P} 146 \mathrm{~A}}$ was monitored by ${ }^{31} \mathrm{P}$ NMR spectroscopy using $\mathrm{AcP}$ as a phosphorylating agent (Supplementary Fig. $9 c, d$ ) ${ }^{31}$. The time courses show a similar overall profile together with the presence of the lag phase and subsequent fitting of the linear segments yielded a $k_{\mathrm{obs}}$ of $70 \pm 30 \mathrm{~s}^{-1}$ for $\beta \mathrm{PGM}_{\mathrm{WT}}$ and a $k_{\mathrm{obs}}$ of $1.1 \pm 0.2 \mathrm{~s}^{-1}$ for $\beta \mathrm{PGM}_{\mathrm{P} 146 \mathrm{~A}}$. The variation between the kinetic parameters derived using the two methods is caused by inhibition resulting from different levels of phosphate-containing species present in the assays. However, the data clearly demonstrate that $\beta_{\mathrm{PGM}} \mathrm{P} 146 \mathrm{~A}$ is active, with a $\sim 20$-fold reduction in $k_{\text {cat }}$, a $\sim 21$-fold increase in $K_{\mathrm{m}}$ for $\beta \mathrm{G} 16 \mathrm{BP}$ and a similar $K_{\mathrm{m}}$ and $K_{\mathrm{i}}$ for $\beta \mathrm{G} 1 \mathrm{P}$, when compared with $\beta \mathrm{PGM}_{\mathrm{WT}}$.

The mechanism of $\beta \mathrm{PGM}_{\mathrm{P} 146 \mathrm{~A}}$ catalytic activity was explored by preparing a TSA complex containing $\mathrm{MgF}_{3}{ }^{-}$and $\mathrm{G}^{2} \mathrm{P}^{29,45}$ and the resulting $\mathrm{PPGM}_{\mathrm{P} 146 \mathrm{~A}}: \mathrm{MgF}_{3}: \mathrm{G} 6 \mathrm{P}$ TSA complex was investigated using NMR spectroscopy. The observed 
${ }^{19} \mathrm{~F}$ chemical shifts are indistinguishable from those of the $\beta \mathrm{PGM}_{\mathrm{WT}}: \mathrm{MgF}_{3}$ :G6P TSA complex (Supplementary Fig. 9e, f) and a ${ }^{1} \mathrm{H}^{15} \mathrm{~N}$-TROSY spectrum peak comparison (BMRB $7234^{26}$ ) indicates an almost identical correspondence between frequencies. Such close agreement allowed a backbone resonance assignment (211 residues-100\%) using 3D HNCACB and 3D HN(CA)CO spectra (BMRB 28097). Residues with the largest chemical shift differences between the $\beta \mathrm{PGM}_{\mathrm{P} 146 \mathrm{~A}}: \mathrm{MgF}_{3}: \mathrm{G} 6 \mathrm{P}$ and $\beta \mathrm{PGM}_{\mathrm{WT}}: \mathrm{MgF}_{3}: \mathrm{G} 6 \mathrm{P}$ TSA complexes are located within $4 \AA$ of residue 146 (K145, A147 and A177) and within $5 \AA$ of residue K145 (S48, V141 and A142) (Supplementary Fig. 4d). Taken together, these results confirm that $\beta \mathrm{PGM}_{\mathrm{P} 146 \mathrm{~A}}$ can assemble a stable and wild-type like $\beta \mathrm{PGM}_{\mathrm{P} 146 \mathrm{~A}}: \mathrm{MgF}_{3}: \mathrm{G} 6 \mathrm{P}$ TSA complex in solution. The

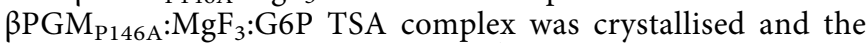
structure was determined to $1.0 \AA$ resolution (PDB 6YDJ; Supplementary Table 1). This complex superimposes very closely with the $\beta_{P_{G M}}{ }_{\mathrm{WT}}: \mathrm{MgF}_{3}$ :G6P TSA complex (non- $\mathrm{H}$ atom $\mathrm{RMSD}=0.18 \AA$, PDB $2 \mathrm{WF}^{29}$ ) and identifies both the positioning of the K145 sidechain in the active site and the cis K145-A146 peptide bond $\left(\omega\right.$ dihedral angle $=14^{\circ}$; compared with $\omega$ dihedral angle $=12^{\circ}$ for the K145-P146 peptide bond in the $\beta_{P G M}{ }_{\mathrm{WT}}: \mathrm{MgF}_{3}: G 6 \mathrm{P}$ TSA complex) (Fig. $4 \mathrm{~b}, \mathrm{~d}$ ). The 6phosphate group of G6P is in the distal site and the trigonal $\mathrm{MgF}_{3}{ }^{-}$moiety mimicking the transferring phosphoryl group is coordinated in the proximal site between D8 (atom O 81 ) and the 1-OH group of G6P. The donor-acceptor distance and the angle of alignment are $4.1 \AA$ and $174^{\circ}$, respectively (compared with $4.3 \AA$ and $176^{\circ}$, respectively for the $\beta \mathrm{PGM}_{\mathrm{WT}}: \mathrm{MgF}_{3}$ :G6P TSA complex). The catalytic $\mathrm{Mg}^{2+}$ ion coordination also has comparable octahedral geometry to the $\beta \mathrm{PGM}_{\mathrm{WT}}: \mathrm{MgF}_{3}: \mathrm{G} 6 \mathrm{P}$ TSA complex and to substrate-free $\beta P_{P_{14}} M_{\mathrm{P}_{146 \mathrm{~A}}}$. Together, these data demonstrate that $\beta \mathrm{PGM}_{\mathrm{P} 146 \mathrm{~A}}$ is able to populate a cis K145-A146 peptide bond and achieve full domain closure with concomitant formation of transition state geometry. In addition, assuming that $\beta$ G16BP binding is diffusion controlled, the increase in $K_{\mathrm{m}}$ for $\beta \mathrm{G} 16 \mathrm{BP}$ in $\beta \mathrm{PGM}_{\mathrm{P} 146 \mathrm{~A}}$ reflects the energetic cost of the trans to cis isomerisation of the K145-A146 peptide bond ${ }^{46}$. As in $\beta \mathrm{PGM}_{\mathrm{WT}}$, these results imply that conformer $A$ of $\beta \mathrm{PGM}_{\mathrm{P} 146 \mathrm{~A}}$ represents the more active form.

BPGM forms two different transient phospho-enzyme species. The possible involvement of conformer B in the modulation of enzyme activity was investigated using real-time NMR methods by comparing the phosphorylation of $\beta$ PGM under saturating conditions of either F16BP (50-100 mM), AcP (60-100 mM) or $\beta$ G16BP (35 mM). Residue A113 is a well-resolved reporter of the relevant species-conformer $\mathrm{A}$ and conformer $\mathrm{B}$, and their phosphorylated counterparts, $\mathrm{A}^{\mathrm{P}}$ and $\mathrm{B}^{\mathrm{P}}$. The carbonyl group of A113 is coordinated by the $\varepsilon$-amino group of K145 (in conformer A) or a water molecule (in conformer B) and its amide proton is hydrogen bonded to the carbonyl group of F7 (adjacent to the D8 nucleophile) (Fig. 4a, b).

On addition of $\mathrm{F} 16 \mathrm{BP}$ to $\beta \mathrm{PGM}_{\mathrm{P} 146 \mathrm{~A}}$, the two dominant species observed are conformer $\mathrm{B}$ and $\mathrm{B}^{\mathrm{P}}$ (Fig. $2 \mathrm{~b}$ ). The presence of conformer $\mathrm{B}$ shows that the phosphorylation rate of $\beta \mathrm{PGM}_{\mathrm{P} 146 \mathrm{~A}}$ is very similar to the dephosphorylation rate of $\mathrm{B}^{\mathrm{P}}$ (through hydrolysis), and only an apparent rate constant can be measured. The apparent rate constant for dephosphorylation was determined to be $0.003 \pm 0.00002 \mathrm{~s}^{-1}$ from the rate of reduction of the free F16BP concentration in ${ }^{1} \mathrm{H}$ NMR experiments. The ${ }^{1} \mathrm{H}$ and ${ }^{15} \mathrm{~N}$ chemical shifts of $\mathrm{B}^{\mathrm{P}}$, assigned using fast acquisition $3 \mathrm{D}$ HNCO and 3D HNCA NMR experiments, mirror those of conformer B, except for the active site residues F7-D8,
A113-A115 and hinge residues T16-E18, owing to their proximity to phosphorylated D8 (Supplementary Fig. 4e). Resonances from the D137-A147 loop show no significant differences between both forms, indicating that the K145-A146 peptide bond is in a trans conformation in $\mathrm{B}^{\mathrm{P}}$ (the conformer $\mathrm{B}$ to $\mathrm{A}^{\mathrm{P}}$ transition results in large chemical shift changes for the D137-A147 loop; Supplementary Fig. 4f). Conformer B and $\mathrm{B}^{\mathrm{P}}$ are also observed when AcP was used as the phosphorylating agent, and a minor population of $\mathrm{A}^{\mathrm{P}}$ is present, correlating with a small increase in the population of $\mathrm{B}^{\mathrm{P}}$ relative to conformer $\mathrm{B}$ (Supplementary Fig. 7b). Identification of $\mathrm{A}^{\mathrm{P}}$ is based on the assignment and structure of the $\beta \mathrm{PGM}_{\mathrm{WT}}: \mathrm{BeF}_{3}$ complex (BMRB 17851; PDB 2WFA ${ }^{35}$ ), where the K145-P146 peptide bond is in a cis conformation and the K145 sidechain is engaged in the active site. Notably, when $\beta$ G16BP was used as the phosphorylating agent, $\mathrm{B}^{\mathrm{P}}$ is not observed (Fig. 2b, Supplementary Fig. $7 \mathrm{~b}$ ). Instead, the $\mathrm{A}^{\mathrm{P}}: \mathrm{G} 6 \mathrm{P}$ and $\mathrm{B}: \beta \mathrm{G} 16 \mathrm{BP}$ complexes are the primarily populated species. The $\mathrm{A}^{\mathrm{P}}$ :G6P complex has similar chemical shifts to the $\beta \mathrm{PGM}_{\mathrm{WT}}: \mathrm{BeF}_{3}$ complex, and the slow exchange between the B: $\beta$ G16BP and the $\mathrm{A}^{\mathrm{P}}: \mathrm{G} 6 \mathrm{P}$ complexes correlates with the measured $k_{\text {cat }}$ values for $\beta \mathrm{PGM}_{\mathrm{P} 146 \mathrm{~A}}$.

In $\beta_{P G M}{ }_{W T}, A^{P}$ is the dominant species observed on addition of F16BP (Fig. 2a, Supplementary Fig. 3c). Therefore, the phosphorylation rate of $\beta_{P G M}$ WT by $\mathrm{F} 16 \mathrm{BP}$ under these conditions must be faster than the hydrolysis rate of $\mathrm{A}^{\mathrm{P}}$ $\left(k_{\text {hydrolysis }}=0.06 \pm 0.006 \mathrm{~s}^{-1}\right)^{31}$. A minor population of the A:F16BP complex is also present, indicating that the phosphorylation rate is slower than the chemical shift difference between the $A^{P}$ and A:F16BP peaks $(140 \mathrm{~Hz})$. Significantly, a minor population of $\mathrm{B}^{\mathrm{P}}$ is also observed. This species is populated transiently ( $\sim \mathrm{min})$ and disappears at longer timeframes, whereas $\mathrm{A}^{\mathrm{P}}$ and the A:F16BP complex populations remain dominant while the phosphorylating agent is at high concentration. Hence, the $\mathrm{B}^{\mathrm{P}}$ population is converting to the more stable $\mathrm{A}^{\mathrm{P}}$ species with a rate constant of $\geq 0.003 \mathrm{~s}^{-1}$, which mirrors the trans to cis isomerisation rate constants of Xaa-Pro peptide bonds in model peptides ${ }^{39}$. Equivalent behaviour is observed when AcP was used as the phosphorylating agent (Supplementary Figs. 3b, $7 \mathrm{a})$, except that an A:AcP complex is not detected. When $\beta$ G16BP was used as a phosphorylating agent, $\mathrm{B}^{\mathrm{P}}$ does not accumulate at any point in the $3 \mathrm{~h}$ time course. The only detectable species is an A:ßG16BP complex (Fig. 2a, Supplementary Figs. 3d, 7a), which is identified by the similarity of chemical shift distribution with the $\beta_{P G M}$ D10N: $\beta$ G16BP complex (BMRB 27174; PDB 5OK131). The low intensity of the A113 peak, along with peaks of other active site residues (Fig. 2a, Supplementary Figs. 3d, 7a), results from millisecond conformational exchange between species within the catalytic cycle, which correlates with the measured $k_{\mathrm{cat}}$ values for $\beta \mathrm{PGM}_{\mathrm{WT}}$. Overall therefore, the consequence of phosphorylation by the reaction intermediate $\beta \mathrm{G} 16 \mathrm{BP}$ is markedly different to that of other phosphorylating agents, in that it generates no detectable $\mathrm{B}^{\mathrm{P}}$ or lag phase, even when the initial population of conformer B is high.

\section{Discussion}

Substrate-free $\beta \mathrm{PGM}_{\mathrm{WT}}$ exists in solution as two distinct conformers with near-equal populations, which differ in the isomerisation state of the K145-P146 peptide bond and interconvert at a rate between $0.003 \mathrm{~s}^{-1}$ and $1.0 \mathrm{~s}^{-1}$. Conformer A contains the cis-isomer of this peptide bond, as observed in the crystal structures of substrate-free $\beta \mathrm{PGM}_{\mathrm{WT}}$, whereas conformer $\mathrm{B}$ contains the trans-isomer, as mimicked by the $\beta \mathrm{PGM}_{\mathrm{P}_{146 \mathrm{~A}}}$ variant. In the crystal structure of $\beta \mathrm{PGM}_{\mathrm{P} 146 \mathrm{~A}}$, the trans $\mathrm{K} 145-\mathrm{A} 146$ peptide bond positions the sidechain of K145 away from the site of phosphoryl transfer, which is significantly different to its location 

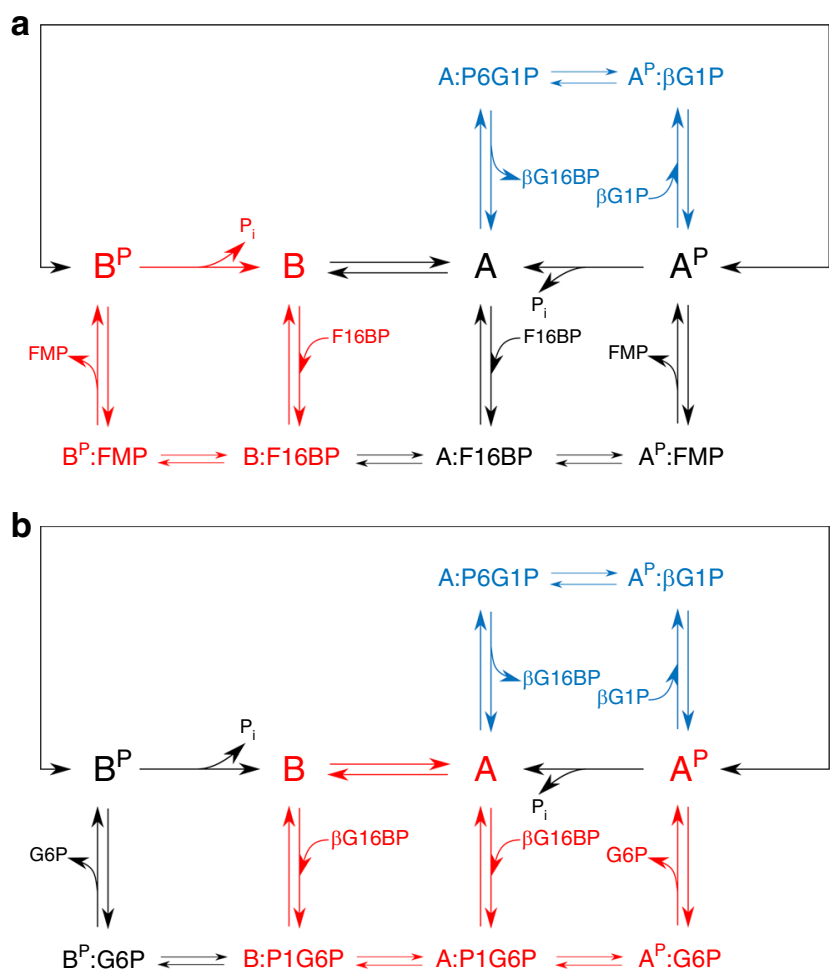

Fig. 6 Kinetic model of $\boldsymbol{\beta P G M}$ activity. $\mathbf{a}$, $\mathbf{b}$ Reaction schemes for $\beta P G M_{W T}$ as conformer $\mathrm{A}$ or conformer $\mathrm{B}$ with different phosphorylating agents. The favoured pathways are shown (red text) for $\beta$ PGM $\mathrm{WT}_{\mathrm{W}}$ with a F16BP as a phosphorylating agent and $\mathbf{b} \beta \mathrm{G} 16 \mathrm{BP}$ as a phosphorylating agent. The $\beta$ G16BP generating steps are highlighted in blue text. Fructose monophosphate (FMP) is either fructose 6-phosphate or fructose 1-phosphate. The complexes X:P1G6P ( $X=A$ or $B)$ and A:P6G1P denote explicitly the orientation of $\beta G 16 B P$ bound in the active site. The doubleheaded arrows connecting $A^{P}$ and $B^{P}$ indicate that these species interconvert with a multi-second exchange rate, similar to that described for the interconversion of conformer A and conformer B.

in all other substrate-free and TSA complex structures reported for $\beta$ PGM $\mathrm{WT}_{\mathrm{WT}}$. The removal of this positively charged amine group from the active site of conformer B disrupts the charge balance in the vicinity of the D8 nucleophile and therefore transition state stability will be severely impaired ${ }^{47,48}$. However, kinetics data for the mutase reaction indicate that $\beta_{P G M}{ }_{P 146 \mathrm{~A}}$ is only $\sim 20$-fold less active than $\beta \mathrm{PGM}_{\mathrm{WT}}$, and has a similar affinity for $\beta \mathrm{G} 1 \mathrm{P}$. In the crystal structure of the $\beta \mathrm{PGM}_{\mathrm{P} 146 \mathrm{~A}}: \mathrm{MgF}_{3}: \mathrm{G} 6 \mathrm{P}$ TSA complex, which mimics the transition state of the phosphoryl transfer step, the K145-A146 peptide bond adopts the cis-isomer and the sidechain of K145 is able to engage in the active site. Hence, conformer A remains the preferred route for phosphoryl transfer in $\beta \mathrm{PGM}_{\mathrm{P} 146 \mathrm{~A}}$, despite it being $\sim 1000$ times less stable than in $\beta \mathrm{PGM}_{\mathrm{WT}}$ because of the trans to cis isomerisation of the K145-A146 peptide bond ${ }^{46}$.

This disruption of the active site has regulatory significance, as conformer $\mathrm{B}$ of $\beta \mathrm{PGM}_{\mathrm{WT}}$ constitutes a substantial population of the resting substrate-free enzyme. In vitro, linear initial kinetics and full activation of the enzyme are achieved only when $\beta$ G16BP is used as the phosphorylating agent. Phosphorylation of both $\beta \mathrm{PGM}_{\mathrm{WT}}$ and $\beta \mathrm{PGM}_{\mathrm{P} 146 \mathrm{~A}}$ with either F16BP or AcP leads to a lag phase, with the lag caused by F16BP lasting 3.5 times longer than that observed with AcP. Moreover, real-time NMR experiments establish that the phosphorylation of both $\beta \mathrm{PGM}_{\mathrm{WT}}$ and $\beta \mathrm{PGM}_{\mathrm{P} 146 \mathrm{~A}}$ with either F16BP or AcP result in the generation of $\mathrm{B}^{\mathrm{P}}$. In $\beta \mathrm{PGM}_{\mathrm{WT}}, \mathrm{B}^{\mathrm{P}}$ isomerises completely into $\mathrm{A}^{\mathrm{P}}$ in $<5 \mathrm{~min}$,

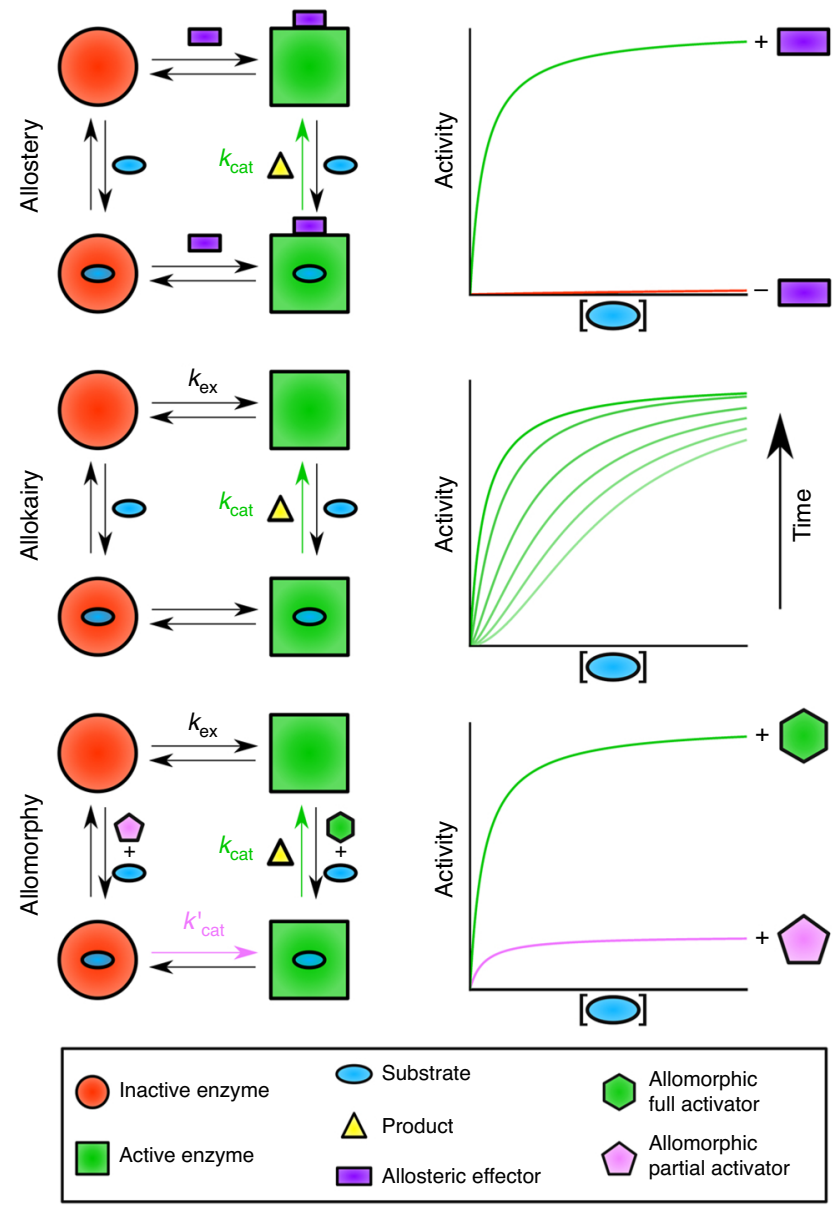

Fig. 7 Mechanisms of regulation and activity profiles in monomeric enzymes. In allostery, binding (or reaction) of an allosteric effector (purple rectangle) outside of the active site shifts the enzyme population from an inactive form (red circle and red profile) to an active form (green square and green profile), which stimulates the transformation of substrate (blue oval) to product (yellow triangle) at the catalytic rate ( $k_{\text {cat, }}$ green arrow). In allokairy, binding of substrate in the active site shifts the enzyme population from an inactive form to an active form, at an exchange rate $\left(k_{\mathrm{ex}}\right)$ that is similar to $k_{\text {cat }}$, resulting in time-dependent activity profiles (gradient of light green to dark green profiles). Following exhaustion of substrate, the enzyme population returns to the original equilibrium position. In allomorphy, reaction of the activating substrate, termed here allomorphic full activator (green hexagon), in the active site shifts the enzyme population from an inactive form to an active form, which stimulates the transformation of the native substrate (blue oval) to product (yellow triangle) at the maximal catalytic rate ( $k_{\text {cat }}$, green arrow and green profile). However, reaction of alternatives substrates, termed here allomorphic partial activators (pink pentagon), in the active site are unable to shift the enzyme population from an inactive form to an active form, resulting in a slower overall catalytic rate ( $k_{\text {cat, }}^{\prime}$ pink arrow and pink profile). The exchange rate $\left(k_{\text {ex }}\right)$ between the two enzyme forms is much slower than $k_{\text {cat. }}$. Following exhaustion of the allomorphic activator, the enzyme population returns to the original equilibrium position.

whereas in $\beta \mathrm{PGM}_{\mathrm{P} 146 \mathrm{~A}}, \mathrm{~B}^{\mathrm{P}}$ is consistently more populated than $\mathrm{A}^{\mathrm{P}}$. In contrast, $\mathrm{B}^{\mathrm{P}}$ is not observed for either $\beta \mathrm{PGM}_{W T}$ or $\beta P M_{P 146 \mathrm{~A}}$ when $\beta G 16 \mathrm{BP}$ is used as the phosphorylating agent. This result demonstrates that phosphorylation with $\beta$ G16BP leads to the stabilisation of conformer $\mathrm{A}$, resulting in production of $\mathrm{A}^{\mathrm{P}}$, regardless of the initial $\beta \mathrm{PGM}$ conformation, even for the $\beta \mathrm{PGM}_{\mathrm{P} 146 \mathrm{~A}}$ variant despite the considerable energetic cost of the conformer B to conformer A transition. Thus, conformer B and 
${ }_{B} \mathrm{P}$ are significantly less-active forms of $\beta P G M$, and the slow transition from $\mathrm{B}^{\mathrm{P}}$ to $\mathrm{A}^{\mathrm{P}}$ is part of the characteristic lag phase observed in the coupled assay kinetics. The longer lag in the F16BP experiments and the observation of a $\beta \mathrm{PGM}_{\mathrm{WT}}$ :F16BP complex are consistent with F16BP having a slower phosphorylation rate than AcP. Therefore, $\beta$ PGM is able to follow alternative kinetic pathways depending on the phosphorylating agent present, with its overall catalytic rate determined by the ratelimiting step in each pathway (Fig. 6a, b).

The response of $\beta$ PGM to different phosphorylating agents also has functional significance. In L. lactis, the sole source of $\beta \mathrm{G} 16 \mathrm{BP}$ is $\beta$ PGM itself. In contrast, F16BP accumulates during glycolysis, reaching a concentration of up to $\sim 50 \mathrm{mM}^{17}$. Hence, F16BP is likely to be the primary source of $\beta$ PGM activation in vivo, with AcP contributing to a lesser extent ${ }^{43,44}$. Correspondingly, a proportion of $\beta$ PGM will populate the less-active $\mathrm{B}^{\mathrm{P}}$ species. Following a switch from glucose to maltose or trehalose metabolism, which will greatly increase the $\beta$ G1P concentration (Supplementary Fig. 1), $\beta$ G16BP will begin to accumulate (Fig. 1, 6a, b). As a result, the conformer $\mathrm{B}$ and $\mathrm{B}^{\mathrm{P}}$ populations will be recruited into the more active $\mathrm{A}^{\mathrm{P}}$ species. This two-state control mechanism allows $L$. lactis to effectively catabolise maltose or trehalose, while the increase in transcription of $\operatorname{pgmB}$ is in progress ${ }^{20}$. Furthermore, when carbohydrate levels are low, a significant proportion of the basal $\beta$ PGM population will be maintained as conformer $\mathrm{B}$, which will consequently reduce the undesirable dephosphorylation of F16BP and also hinder the conversion of G6P to $\beta$ G1P.

The multi-second substrate-dependent non-allosteric conformational exchange mediated through cis-trans proline isomerisation seen in $\beta$ PGM represents a mechanism of posttranslational enzyme regulation. This regulation mechanism relies on the existence of alternative pathways with different ratelimiting steps, where the catalytic rate depends on the capacity of an activator, acting as a substrate, to bias the enzyme population towards the fastest pathway, by stabilising the most active conformation (Fig. 7). Similar to allostery and allokairy, this mechanism depends on the ability of the enzyme to adopt at least two conformations with distinct activities, but does not require the binding of an additional effector to the protein, nor an equivalence between the conformational exchange rate and the catalytic rate. We suggest the name allomorphy for this mechanism, from the greek allos meaning other and morphe meaning form, in keeping with the previously described allostery and allokairy mechanisms ${ }^{15}$.

Allomorphy may modulate the activity of other monomeric enzymes with hysteretic behaviour, i.e., those that exhibit a burst or lag phase in their kinetic profile ${ }^{49}$. Several theoretical models have been put forward to rationalise hysteretic behaviour, such as the mnemonic ${ }^{50}$ and the ligand-induced slow transition ${ }^{51}$ models, but detailed structural-based molecular mechanisms have proved elusive. To our knowledge, only one such mechanism, allokairy in human glucokinase, has been described in detail ${ }^{15,16}$. Allomorphy is a different fine control regulatory mechanism and is potentially widespread, at least across phosphomutases; for example, both rabbit muscle and L. lactis a-phosphoglucomutases appear to be hysteretic enzymes ${ }^{52,53}$, but belong to very different protein superfamilies. Like $\beta$ PGM, these enzymes require a phosphorylating agent to initiate the catalytic cycle and, for the latter, the use of the reaction intermediate results in linear kinetics, whereas alternative phosphorylating agents produce a lag phase in their kinetic profiles. Similarly, a-phosphomannomutase from Galdieria sulphuraria, which also requires the addition of a phosphorylating agent to initiate the catalytic cycle, exhibits linear kinetics when $\alpha$-mannose 1 -phosphate and $\alpha$-mannose 1,6bisphosphate (or $\alpha$-glucose 1-phosphate and aG16BP) are included in the reaction, but has a lag phase when there is a mismatch between substrate and phosphorylating agent, or when F16BP is used as the phosphorylating agent ${ }^{54}$. All of these observations are consistent with the presence of allomorphic control.

In summary, allomorphy is a fine control mechanism by which part of an enzyme population is maintained in a more latent state, and is quickly switchable between high and low activity levels, without allosteric effectors. It delivers important control with which $L$. lactis is able to reconcile two seemingly contradictory requirements: the need to maximise its responsiveness to changes in carbohydrate source and the need to minimise unproductive diversion of valuable metabolites.

\section{Methods}

$\beta$-phosphoglucomutase ( $\beta$ PGM) expression and purification. Wild-type $\beta$ PGM $\left(\beta \mathrm{PGM}_{\mathrm{WT}}\right)$ and the $\mathrm{P} 146 \mathrm{~A}$ variant $\left(\beta_{\mathrm{PGM}} \mathrm{P}_{\mathrm{P} 16 \mathrm{~A}}\right)$ proteins were expressed using either ${ }^{15} \mathrm{~N}$ or ${ }^{2} \mathrm{H}^{15} \mathrm{~N}^{13} \mathrm{C}$ isotopic enrichment ${ }^{55}$ and purified using methodology that minimised the presence of contaminating phosphoryl transfer enzymes (e.g., phosphoglucose isomerase and $\beta$ PGM from E. coli) ${ }^{31,42}$. The $\beta \mathrm{PGM}_{\mathrm{WT}}$ and $\beta_{\mathrm{PGM}} \mathrm{P}_{146 \mathrm{~A}}$ genes were cloned into the $\mathrm{pET}-22 \mathrm{~b}(+)$ plasmid, transformed into $E$. coli strain BL21(DE3) cells and expressed in defined isotopically labelled minimal media. Cells were grown at $37^{\circ} \mathrm{C}$ with shaking until $\mathrm{OD}_{600 \mathrm{~nm}}=0.6$, then cooled at $25^{\circ} \mathrm{C}$ and induced with $0.5 \mathrm{mM}$ isopropyl $\beta$-D-1-thiogalactopyranoside for a further $18 \mathrm{~h}$. Cells were harvested by centrifugation at $10,000 \mathrm{rpm}$ for $10 \mathrm{~min}$. The cell pellet was resuspended in ice-cold lysis buffer $\left(50 \mathrm{mM} \mathrm{K}^{+}\right.$HEPES ( $\left.\mathrm{pH} 7.2\right), 2 \mathrm{mM}$ $\mathrm{NaN}_{3}, 1 \mathrm{mM}$ EDTA) supplemented with cOmplete ${ }^{\mathrm{Tw}}$ protease inhibitor cocktail and lysed by six cycles of sonication. The cell lysate was cleared by centrifugation at $20,000 \mathrm{rpm}$ for $35 \mathrm{~min}$ at $4^{\circ} \mathrm{C}$. The supernatant was filtered using a $0.22 \mu \mathrm{m}$ syringe filter and loaded onto a DEAE-Sepharose fast flow anion-exchange column. Proteins bound to the column were eluted with a gradient of $0-50 \%$ lysis buffer containing $1 \mathrm{M} \mathrm{NaCl}$. Fractions containing $\beta$ PGM were purified further using a Hiload 26/600 Superdex 75 size-exclusion column previously equilibrated with lysis buffer containing $1 \mathrm{M} \mathrm{NaCl}$. Final fractions were pooled, buffer exchanged into $50 \mathrm{mM} \mathrm{K}^{+}$HEPES buffer (pH 7.2) containing $2 \mathrm{mM} \mathrm{NaN}_{3}$ and concentrated to $\sim 1.6 \mathrm{mM}$ for storage at $-20^{\circ} \mathrm{C}$.

Reagents. Unless otherwise stated, reagents were purchased from Sigma-Aldrich, GE Healthcare, Melford Laboratories or CortecNet. $\beta$ G1P was synthesised enzymatically from maltose using maltose phosphorylase (EC 2.4.1.8) ${ }^{31}$. A solution of maltose $(600 \mathrm{mM})$ was incubated overnight with 1.2 units $\mathrm{mL}^{-1}$ maltose phosphorylase in $0.5 \mathrm{M}$ sodium phosphate buffer $(\mathrm{pH} 7.0)$ at $30^{\circ} \mathrm{C}$ and $\beta \mathrm{G} 1 \mathrm{P}$ production was confirmed using ${ }^{31} \mathrm{P}$ NMR spectroscopy. Maltose phosphorylase was removed using a Vivaspin ( $5 \mathrm{kDa}$ MWCO) and the resulting flow-through was used without further purification. $\beta \mathrm{G} 16 \mathrm{BP}$ was produced enzymatically from $\beta \mathrm{G} 1 \mathrm{P}$ and AcP using the D170N variant of $\beta$ PGM ( $\beta P_{\text {PGM }}{ }_{\text {D170N }}$; expressed and purified as detailed above $)^{56}$. $\beta \mathrm{G} 1 \mathrm{P}$ and AcP were incubated with $\beta \mathrm{PGM}_{\mathrm{D} 170 \mathrm{~N}}$ for $4 \mathrm{~h}$ at $25^{\circ} \mathrm{C}$ and the reaction was quenched by heating at $90^{\circ} \mathrm{C}$ for $10 \mathrm{~min}$. $\beta \mathrm{G} 16 \mathrm{BP}$ was purified using barium salt precipitation.

NMR spectroscopy. ${ }^{1} \mathrm{H}^{15} \mathrm{~N}$-TROSY NMR spectra of $\beta \mathrm{PGM}_{\mathrm{WT}}$ and $\beta \mathrm{PGM}_{\mathrm{P} 146 \mathrm{~A}}$ were acquired at $298 \mathrm{~K}$ using $0.5-1 \mathrm{mM}{ }^{15} \mathrm{~N}-\beta \mathrm{PGM}$ in standard NMR buffer (50 $\mathrm{mM} \mathrm{K}^{+}$HEPES (pH 7.2), $5 \mathrm{mM} \mathrm{MgCl}_{2}, 2 \mathrm{mM} \mathrm{NaN}_{3}$ with $10 \%(\mathrm{v} / \mathrm{v}){ }^{2} \mathrm{H}_{2} \mathrm{O}$ and 1 mM TSP). Typically, ${ }^{1} \mathrm{H}^{15} \mathrm{~N}$-TROSY spectra were accumulations of 16 transients, with 256 increments and spectral widths of $32-36 \mathrm{ppm}$ centred at $120 \mathrm{ppm}$ in the indirect ${ }^{15} \mathrm{~N}$ dimension. ${ }^{1} \mathrm{H}^{15} \mathrm{~N}$-TROSY-based ZZ-exchange experiments were performed at mixing times of $100,300,500$ and 900 ms. Rapid acquisition ${ }^{1} \mathrm{H}^{15} \mathrm{~N}$ BEST-TROSY experiments to monitor the steady-state behaviour of ${ }^{15} \mathrm{~N}-\beta \mathrm{PGM}_{\mathrm{WT}}$ $(0.2 \mathrm{mM})$ and ${ }^{15} \mathrm{~N}-\beta \mathrm{PGM}_{\mathrm{P} 146 \mathrm{~A}}(0.2 \mathrm{mM})$ were acquired in standard kinetic buffer (200 mM K ${ }^{+}$HEPES (pH 7.2), $5 \mathrm{mM} \mathrm{MgCl}_{2}, 2 \mathrm{mM} \mathrm{NaN}_{3}$ with $10 \%(\mathrm{v} / \mathrm{v}){ }^{2} \mathrm{H}_{2} \mathrm{O}$ and $1 \mathrm{mM}$ TSP) containing either $50-100 \mathrm{mM}$ F16BP, $60-100 \mathrm{mM} \mathrm{AcP}$ or $35 \mathrm{mM}$ $\beta$ G16BP. The ${ }^{1} \mathrm{H}^{15} \mathrm{~N}$ BEST-TROSY spectra were recorded at $298 \mathrm{~K}$ using a Bruker $600 \mathrm{MHz}$ Neo spectrometer equipped with a 5-mm TCI cryoprobe and $z$ axis gradients as 11 min experiments ( 16 transients, 128 increments and a recycle delay of $0.2 \mathrm{~s}$ ) with selective ${ }^{1} \mathrm{H}$ pulses centred on the amide region $(8.3 \mathrm{ppm})$. Excitation pulses $\left(90^{\circ}\right)$ were $1.7 \mathrm{~ms}$ (pulse shape Eburp2), whereas refocusing pulses $\left(180^{\circ}\right)$ were $1.4 \mathrm{~ms}$ (pulse shape Reburp). The experimental dead-time was $\sim 5 \mathrm{~min}$.

For $\beta_{P G M}$ P $146 \mathrm{~A}_{\text {a }}$ prepared in standard kinetic buffer containing $50 \mathrm{mM}$ F16BP, $\mathrm{B}^{\mathrm{P}}$ dephosphorylation was monitored at $298 \mathrm{~K}$ by consecutive one-dimensional ${ }^{1} \mathrm{H}$ NMR experiments recorded with 16 transients, a $1 \mathrm{~s}$ recycle delay and a spectral width of $32 \mathrm{ppm}$ centred on the water signal. Following $0.3 \mathrm{~Hz}$ Lorentzian apodisation and baseline correction, normalised integral values of the F16BP peak $(4.22-4.15 \mathrm{ppm})$ were plotted against time to give a kinetic profile. The initial linear steady-state portion of the kinetic profile was fitted using a linear least-squares fitting algorithm included in MATLAB 2018a to derive an apparent

dephosphorylation rate constant. 
To observe the species present immediately following the addition of phosphorylating agent to $\beta \mathrm{PGM}_{\mathrm{WT}}$, NMR experiments were recorded with the use of a homemade rapid mixing device. The equipment comprised a $2 \mathrm{~m}$ length of 0.8 $\mathrm{mm}$ internal diameter EFTE tubing (GE Healthcare), connected at one end to a 1 $\mathrm{mL}$ syringe and inserted at the other end through the lid of an NMR tube. The tubing was loaded with phosphorylating agent $(550 \mu \mathrm{L} 100 \mathrm{mM}$ F16BP or $250 \mu \mathrm{L}$ $320 \mathrm{mM}$ AcP, prepared in standard kinetic buffer) and a small, additional volume of air was drawn in to prevent premature mixing of the phosphorylating agent with the $550 \mu \mathrm{L} 1.2 \mathrm{mM}{ }^{15} \mathrm{~N}-\beta \mathrm{PGM}_{\mathrm{WT}}$ sample prepared in standard kinetic buffer. The rapid mixing device was loaded into a Bruker $600 \mathrm{MHz}$ Neo spectrometer and allowed to equilibrate thermally at $298 \mathrm{~K}$. Following mixing by syringe action of the phosphorylating agent (final concentration: $50 \mathrm{mM} \mathrm{F16BP}$ or $100 \mathrm{mM} \mathrm{AcP}$ ) with the $\beta \mathrm{PGM}_{\mathrm{WT}}$ sample, the spectrometer was locked (with $\sim 7 \%(\mathrm{v} / \mathrm{v}){ }^{2} \mathrm{H}_{2} \mathrm{O}$ ), tuned and shimmed, and the ${ }^{1} \mathrm{H} 90^{\circ}$ pulse length was calibrated. A series of ${ }^{1} \mathrm{H}^{15} \mathrm{~N}$ BESTTROSY spectra were recorded as $142 \mathrm{~s}$ experiments (4 transients, 128 increments and a recycle delay of $0.15 \mathrm{~s}$ ). The experimental dead-time was $\sim 156 \mathrm{~s}$

Multi-dimensional heteronuclear NMR spectra for ${ }^{1} \mathrm{H},{ }^{15} \mathrm{~N}$ and ${ }^{13} \mathrm{C}$ backbone resonance assignment of ${ }^{2} \mathrm{H}^{15} \mathrm{~N}^{13} \mathrm{C}-\beta \mathrm{PGM}_{\mathrm{WT}}$ in standard NMR buffer containing $10 \mathrm{mM}$ tris were acquired at $298 \mathrm{~K}$ on a Bruker $800 \mathrm{MHz}$ Avance III spectrometer equipped with a 5-mm TCI cryoprobe and $z$ axis gradients. The standard Bruker suite of ${ }^{1} \mathrm{H}^{15} \mathrm{~N}$-TROSY and 3D TROSY-based constant time experiments were acquired (HNCO, HN(CA)CO, HNCA, HN(CO)CA, HNCACB, HN(CO)CACB) using non-uniform sampling (NUS) with a multi-dimensional Poisson Gap scheduling strategy with exponential weighting ${ }^{57}$. NUS data were reconstructed using multi-dimensional decomposition in TopSpin $3^{58}$. Backbone resonance assignments for conformer A and conformer B present simultaneously in the spectra were obtained using a simulated annealing algorithm employed by the asstools assignment program ${ }^{55}$ and assignments were confirmed using sequential backbone amide to amide correlations obtained from TROSY-based (H)N(COCA) $\mathrm{NNH}$ and $\mathrm{H}(\mathrm{NCOCA}) \mathrm{NNH}$ experiments ${ }^{59}$. Multi-dimensional heteronuclear NMR spectra for ${ }^{1} \mathrm{H},{ }^{15} \mathrm{~N}$ and ${ }^{13} \mathrm{C}$ backbone resonance assignment of the ${ }^{2} \mathrm{H}^{15} \mathrm{~N}^{13} \mathrm{C}-\beta \mathrm{PGM}_{\mathrm{P} 146 \mathrm{~A}}: \mathrm{MgF}_{3}$ :G6P TSA complex in standard NMR buffer containing $15 \mathrm{mM} \mathrm{NaF}$ and $10 \mathrm{mM} \mathrm{G} 6 \mathrm{P}$ were acquired at $298 \mathrm{~K}$ on a Bruker 800 $\mathrm{MHz}$ Avance I spectrometer equipped with a 5-mm TXI probe and $z$ axis gradients. ${ }^{1} \mathrm{H}^{15} \mathrm{~N}$-TROSY and 3D TROSY-based constant time experiments were acquired ( $\mathrm{HN}(\mathrm{CA}) \mathrm{CO}$ and $\mathrm{HNCACB}$ ) and backbone resonance assignments were obtained using asstools ${ }^{55}$. Multi-dimensional heteronuclear NMR spectra for ${ }^{1} \mathrm{H},{ }^{15} \mathrm{~N}$ and ${ }^{13} \mathrm{C}$ backbone resonance assignment of phosphorylated ${ }^{2} \mathrm{H}^{15} \mathrm{~N}^{13} \mathrm{C}-\beta \mathrm{PGM} \mathrm{P}_{\mathrm{P} 146 \mathrm{~A}}$ in standard kinetic buffer containing $75-100 \mathrm{mM}$ F16BP were acquired at $298 \mathrm{~K}$ on a Bruker $800 \mathrm{MHz}$ Neo spectrometer equipped with a 5-mm TXI probe and $z$ axis gradients. ${ }^{1} \mathrm{H}^{15} \mathrm{~N}$-TROSY and $3 \mathrm{D}$ TROSY-based constant time experiments were acquired (HNCO and HNCA) using NUS with a multi-dimensional Poisson Gap scheduling strategy with exponential weighting ${ }^{57}$. NUS data were reconstructed using multi-dimensional decomposition in TopSpin $4^{58}$. TROSY resonances were assigned by comparing the correlated ${ }^{13} \mathrm{C}$ chemical shifts with those of $\beta \mathrm{PGM}_{\mathrm{P} 146 \mathrm{~A}}\left(\mathrm{BMRB} 27920^{42}\right.$ ) and the $\beta_{\mathrm{PGM}_{\mathrm{WT}}: \mathrm{BeF}_{3} \text { complex }}$ (BMRB $17851^{35}$ ). Experiments were processed using TopSpin (Bruker) or FELIX (Felix NMR, Inc.) and NMR figures were prepared using FELIX. ${ }^{1} \mathrm{H}$ chemical shifts were referenced relative to the internal TSP signal resonating at $0.0 \mathrm{ppm}$, and ${ }^{13} \mathrm{C}$ and ${ }^{15} \mathrm{~N}$ and chemical shifts were referenced indirectly using nuclei-specific gyromagnetic ratios. Differences in chemical shift were calculated as: $\Delta \delta=\left[\left(\delta_{\mathrm{HN}-X}-\delta_{\mathrm{HN}-Y}\right)^{2}+\left(0.12 \times\left(\delta_{\mathrm{N}-X^{-}} \delta_{\mathrm{N}-\mathrm{Y}}\right)\right)^{2}\right]^{1 / 2}$, where $X$ and $Y$ are the two species being compared.

Reaction kineltics for $\beta \mathrm{PGM}_{\mathrm{P} 146 \mathrm{~A}}$-catalysed reactions were followed using a Bruker $500 \mathrm{MHz}$ Avance DRX spectrometer (operating at $202.456 \mathrm{MHz}$ for ${ }^{31} \mathrm{P}$ ) equipped with a room-temperature broadband probe. The equilibration of $10 \mathrm{mM}$ $\beta \mathrm{G} 1 \mathrm{P}$ with G6P by $1-3 \mu \mathrm{M} \beta \mathrm{PGM}_{\mathrm{P} 146 \mathrm{~A}}$ was measured in standard kinetic buffer at $298 \mathrm{~K}$. The reaction was initiated by and timed from the addition of $20 \mathrm{mM} \mathrm{AcP}$ and monitored by the acquisition of consecutive ${ }^{31} \mathrm{P}$ spectra without protonphosphorus decoupling with 256 transients and a $1 \mathrm{~s}$ recycle delay. A spectral width of $50 \mathrm{ppm}$ centred at $-10 \mathrm{ppm}$ enabled the observation of the relevant phosphorus signals. Normalised integral values of both the $\beta \mathrm{G} 1 \mathrm{P}$ and G6P peaks following baseline correction and $5 \mathrm{~Hz}$ Lorentzian apodisation were plotted against time to give kinetic profiles. The linear steady-state portion of the G6P integral data was fitted using a linear least-squares fitting algorithm to derive the observed rate constant, $k_{\text {obs }}$

One-dimensional ${ }^{19} \mathrm{~F}$ NMR experiments were acquired at $298 \mathrm{~K}$ on a Bruker $500 \mathrm{MHz}$ Avance III spectrometer (operating at $470.536 \mathrm{MHz}$ for ${ }^{19} \mathrm{~F}$ ) equipped with a 5-mm QCI-F cryoprobe and $z$ axis gradients. Samples were prepared using $0.5 \mathrm{mM}{ }^{15} \mathrm{~N}-\beta \mathrm{PGM}_{\mathrm{WT}}$ or ${ }^{15} \mathrm{~N}-\beta \mathrm{PGM}_{\mathrm{P} 146 \mathrm{~A}}$ in standard NMR buffer (without $10 \%$ (v/v) ${ }^{2} \mathrm{H}_{2} \mathrm{O}$ ) containing $15 \mathrm{mM} \mathrm{NaF}$ and $10 \mathrm{mM}$ G6P. The spectrometer lock was provided by ${ }^{2} \mathrm{H}_{2} \mathrm{O}$ sealed inside a glass capillary tube inserted into the sample tube. Typically, $\sim 6000$ transients were acquired without ${ }^{1} \mathrm{H}$ decoupling over a spectral width of $120 \mathrm{ppm}$ and were processed with sinebell functions shifted by $60^{\circ}$.

For NMR experiments conducted in filtered milk, fresh skimmed bovine milk purchased from a local supermarket was filtered using a $10 \mathrm{kDa}$ MWCO Vivaspin (Sartorius) to remove fat micelles and milk proteins. A $1 \mathrm{mM}{ }^{15} \mathrm{~N}-\beta \mathrm{PGM}_{\mathrm{WT}}$ sample prepared in standard NMR buffer was diluted fivefold with the resulting milk flow-through and $10 \%(\mathrm{v} / \mathrm{v}){ }^{2} \mathrm{H}_{2} \mathrm{O}$ and $1 \mathrm{mM}$ TSP were added to the sample. Experiments were acquired at $298 \mathrm{~K}$ on a Bruker $800 \mathrm{MHz}$ Avance I spectrometer equipped with a 5-mm TXI probe and $z$ axis gradients. The $\mathrm{pH}$ of the sample was estimated as pH 6.8 using the residual ${ }^{1} \mathrm{H}$ resonances of HEPES buffer originating from the standard NMR buffer.

For NMR experiments conducted in the absence of salt, a $1.4 \mathrm{mM}$

${ }^{15} \mathrm{~N}-\beta \mathrm{PGM}_{\mathrm{WT}}$ sample in standard NMR buffer containing an additional $200 \mathrm{mM}$ $\mathrm{NaCl}$ was buffer-exchanged into freshly produced deionised water $(18.2 \mathrm{M} \Omega . \mathrm{cm}$, Purelab Classic, Elga-Veolia), with an equivalent dilution of the previous buffer by a factor of $18.7 \times 10^{6}$. The resulting sample contained $0.9 \mathrm{mM} \beta \mathrm{PGM}_{\mathrm{WT}}$ at $\mathrm{pH} 6.3$ and was supplemented with $10 \%(\mathrm{v} / \mathrm{v}){ }^{2} \mathrm{H}_{2} \mathrm{O}$ for the deuterium lock. Experiments were acquired at $298 \mathrm{~K}$ on a Bruker $800 \mathrm{MHz}$ Avance I spectrometer equipped with a $5-\mathrm{mm}$ TXI probe and $z$ axis gradients.

Kinetic experiments using coupled assays. All kinetic assays for $\beta \mathrm{PGM}_{\mathrm{WT}}$ and $\beta P M_{P 146 \mathrm{~A}}$ were conducted at $298 \mathrm{~K}$ using a FLUOstar OMEGA microplate reader and the BMG LABTECH Reader Control Software (version 5.11) (BMG Labtech) in standard kinetic buffer $\left(200 \mathrm{mM} \mathrm{K}^{+}\right.$HEPES (pH 7.2), $5 \mathrm{mM} \mathrm{MgCl}_{2}, 1 \mathrm{mM} \mathrm{NaN}_{3}$ ) in a $160 \mu \mathrm{L}$ reaction volume. The rate of G6P production was measured indirectly using a glucose 6-phosphate dehydrogenase (G6PDH) coupled assay, in which G6P is oxidised and concomitant $\mathrm{NAD}^{+}$reduction is monitored by the increase in absorbance at $340 \mathrm{~nm}$ (NADH extinction coefficient $\left.=6220 \mathrm{M}^{-1} \mathrm{~cm}^{-1}\right) . \beta \mathrm{PGM}_{\mathrm{WT}}$ and $\beta \mathrm{PGM}_{\mathrm{P} 146 \mathrm{~A}}$ concentrations were determined using a NanoDrop OneC spectrophotometer (Thermo Scientific) and diluted accordingly ( $\beta$ PGM extinction coefficient $\left.=19,940 \mathrm{M}^{-1} \mathrm{~cm}^{-1}\right)$. For the determination of $k_{\text {cat }}$ and $K_{\mathrm{m}}$ values for $\beta \mathrm{PGM}_{\mathrm{WT}}$, the reaction was initiated by dilution of the enzyme prepared in standard kinetic buffer to a final concentration of $1 \mathrm{nM} \beta \mathrm{PGM}_{\mathrm{WT}}$ in solutions of $1 \mathrm{mM}$ $\mathrm{NAD}^{+}$and 5 units $\mathrm{mL}^{-1} \mathrm{G} 6 \mathrm{PDH}$ and variable concentrations of $\beta \mathrm{G} 1 \mathrm{P}(10,20,30$, $50,70,100,150,200,300,500,700 \mu \mathrm{M})$ and $\beta \mathrm{G} 16 \mathrm{BP}(0.4,1,2,5,10 \mu \mathrm{M})$. For the determination of $k_{\text {cat }}$ and $K_{\mathrm{m}}$ values for $\beta \mathrm{PGM}_{\mathrm{P} 146 \mathrm{~A}}$, the reaction was initiated by dilution of the enzyme prepared in standard kinetic buffer to a final concentration of $100 \mathrm{nM} \beta \mathrm{PGM}_{\mathrm{P} 146 \mathrm{~A}}$ in solutions of $1 \mathrm{mM} \mathrm{NAD}{ }^{+}$and 5 units $\mathrm{mL}^{-1} \mathrm{G} 6 \mathrm{PDH}$ and variable concentrations of $\beta \mathrm{G} 1 \mathrm{P}(5,10,15,20,30,50,70,100,200,300,500 \mu \mathrm{M})$ and $\beta$ G16BP $(2,5,10,35,50,100 \mu \mathrm{M})$. The initial rate of G6P production was fitted using a linear least-squares fitting algorithm to determine the reaction velocity $\left(v_{0}\right)$ at each $\beta \mathrm{G} 1 \mathrm{P}$ and $\beta \mathrm{G} 16 \mathrm{BP}$ concentration at a total enzyme concentration $\left(E_{\mathrm{T}}\right)$. Mean data from triplicate measurements were subsequently globally fitted to Eq. $1^{28}$, which is derived for a ping-pong mechanism and adapted to account for $\beta \mathrm{G} 1 \mathrm{P}$ inhibition $\left(K_{\mathrm{i}}\right)$ to calculate $k_{\text {cat }}$ and individual $K_{\mathrm{m}}$ values $\left(K_{\beta G 1 P}\right.$ and $K_{\beta G 16 \mathrm{BP}}$ ), with their corresponding standard deviations, using an in-house python non-linear least-squares fitting program.

$$
v_{0}=\frac{k_{\mathrm{cat}}\left[E_{T}\right][\beta \mathrm{G} 1 \mathrm{P}][\beta \mathrm{G} 16 \mathrm{BP}]}{[\beta \mathrm{G} 1 \mathrm{P}][\beta \mathrm{G} 16 \mathrm{BP}]+K_{\beta \mathrm{G} 1 \mathrm{P}}[\beta \mathrm{G} 16 \mathrm{BP}]+K_{\beta \mathrm{G} 16 \mathrm{BP}}[\beta \mathrm{G} 1 \mathrm{P}]\left(\frac{K_{i}+[\beta \mathrm{G} 1 \mathrm{P}]}{K_{i}}\right)}
$$

Kinetic experiments demonstrating the effect of different phosphorylating agents were conducted by the addition of either $5 \mathrm{nM} \beta \mathrm{PGM}_{\mathrm{WT}}$ or $200 \mathrm{nM}$ $\beta \mathrm{PGM}_{\mathrm{P} 146 \mathrm{~A}}$ to solutions containing either $1 \mathrm{mM}$ F16BP, $8 \mathrm{mM} \mathrm{AcP}$ or $10 \mu \mathrm{M}$ $\beta$ G16BP, together with $1 \mathrm{mM} \mathrm{NAD}^{+}, 5$ units $\mathrm{mL}^{-1} \mathrm{G} 6 \mathrm{PDH}$ and $50 \mu \mathrm{M} \beta \mathrm{G} 1 \mathrm{P}$. F16BP represents an equilibrium mixture of an $\alpha$-anomer (15\%), a $\beta$-anomer (81\%) and two open chain forms with an interconversion rate of $8 \mathrm{~s}^{-1} 60$.

X-ray crystallography. For the crystallisation experiments of $\beta \mathrm{PGM}_{\mathrm{WT}}$, $\beta \mathrm{PGM}_{\mathrm{P} 146 \mathrm{~A}}$, the $\beta \mathrm{PGM}_{\mathrm{P} 146 \mathrm{~A}}: \mathrm{MgF}_{3}: \mathrm{G} 6 \mathrm{P}$ TSA complex and the $\beta \mathrm{PGM}_{\mathrm{WT}}$ :citrate complex, frozen aliquots of $\beta \mathrm{PGM}_{\mathrm{WT}}$ or $\beta \mathrm{PGM}_{\mathrm{P} 146 \mathrm{~A}}$ in standard native buffer (50 $\mathrm{mM} \mathrm{K}^{+}$HEPES ( $\mathrm{pH}$ 7.2), $5 \mathrm{mM} \mathrm{MgCl}_{2}, 2 \mathrm{mM} \mathrm{NaN}_{3}$ ) were thawed on ice and centrifuged briefly to pellet insoluble material. For the $\beta \mathrm{PGM}_{\mathrm{P}_{146 \mathrm{~A}}}: \mathrm{MgF}_{3}: \mathrm{G} 6 \mathrm{P}$ TSA complex, $15 \mathrm{mM} \mathrm{NaF}$ and $10 \mathrm{mM} \mathrm{G} 6 \mathrm{P}$ were added to the $\beta \mathrm{PGM}_{\mathrm{P} 146 \mathrm{~A}}$ sample, whereas for the $\beta \mathrm{PGM}_{\mathrm{WT}}$ :citrate complex, $50 \mathrm{mM}$ citrate was added to the $\beta \mathrm{PGM}_{\mathrm{WT}}$ sample. Solutions were adjusted to a final protein concentration of 0.4-0.6 mM, incubated for $1 \mathrm{~h}$ and mixed 1:1 with precipitant (24-34\% (w/v) PEG 4000, $200 \mathrm{mM}$ sodium acetate and $100 \mathrm{mM}$ tris- $\mathrm{HCl}(\mathrm{pH}$ 7.5)). Crystals were grown at $290 \mathrm{~K}$ by hanging-drop vapour diffusion using a $2 \mu$ drop suspended on a siliconised glass cover slip above a $700 \mu \mathrm{L}$ well. Rod-shaped or large plate crystals grew typically over several days. Crystals were harvested using a mounted LithoLoop (Molecular Dimensions Ltd) and were cryo-protected in their mother liquor containing an additional 25\% (v/v) ethylene glycol (and $50 \mathrm{mM}$ citrate for the $\beta \mathrm{PGM}_{\mathrm{WT}}$ :citrate crystals) prior to plunging into liquid nitrogen. Diffraction data were collected at $100 \mathrm{~K}$ on the MX beamlines at the Diamond Light Source (DLS), Oxfordshire, United Kingdom.

Data were processed using the xia2 pipeline ${ }^{61}$ and resolution cutoffs were applied using CC-half values and Aimless ${ }^{62}$. The crystals diffracted in the $\mathrm{P}_{1} 2_{1} 2_{1}$ spacegroup, with cell dimensions that varied depending on the degree of enzyme closure. Structures were determined by molecular replacement with MolRep (version 11$)^{63}$ using the highest resolution model with the most appropriate cap and core domain relationship as a search model. Model building was carried out in COOT (version 0.8.8) ${ }^{64}$ with ligands not included until the final rounds of refinement with REFMAC $5^{65}$ so that they could be built into unbiased difference Fourier maps. The $\beta \mathrm{PGM}_{\mathrm{P} 146 \mathrm{~A}}: \mathrm{MgF}_{3}: \mathrm{G} 6 \mathrm{P}$ TSA complex structure was refined with anisotropic B-factors, whereas both the $\beta_{\mathrm{PGM}} \mathrm{WT}$ structures and the substrate-free $\beta \mathrm{PGM}_{\mathrm{P} 146 \mathrm{~A}}$ structure were refined isotropically. Structure validation was carried out in COOT and MolProbity (version 4.4) ${ }^{66}$. Superpositions and crystallographic 
figures were prepared using PyMOL (The PyMOL Molecular Graphics System, version 1.8, Schrödinger, LLC). To confirm the isomerisation state of the K145-A146 peptide bond in the structures of substrate-free $\beta \mathrm{PGM}_{\mathrm{P} 146 \mathrm{~A}}$ and the

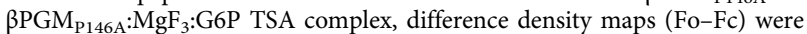
generated using REFMAC5 with the S144-P148 segment omitted from the final structures. Omit map figures were prepared using CCP4mg (version 2.10.9) ${ }^{67}$. Additional details for X-ray crystallography data collection, data processing and refinement are provided in Supplementary Table 1.

\section{Data availability}

Data supporting the findings of this manuscript are available from the corresponding author upon reasonable request. The atomic coordinates and structure factors have been deposited in the Protein Data Bank (www.rcsb.org) with the following codes: $\beta \mathrm{PGM}_{\mathrm{WT}}$ :citrate complex (PDB 6YDM), substrate-free $\beta \mathrm{PGM}_{\mathrm{WT}}$ (PDB 6YDL),

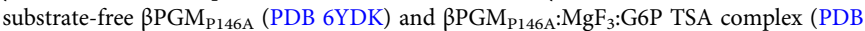
6YDJ). The NMR chemical shifts have been deposited in the BioMagResBank (www. bmrb.wisc.edu) with the following accession numbers: substrate-free $\beta \mathrm{PGM}_{\mathrm{WT}}$ conformer A (BMRB 28095), substrate-free $\beta \mathrm{PGM}_{\mathrm{WT}}$ conformer B (BMRB 28096) and $\beta \mathrm{PGM}_{\mathrm{P} 146 \mathrm{~A}}: \mathrm{MgF}_{3}: \mathrm{G} 6 \mathrm{P}$ TSA complex (BMRB 28097).

\section{Code availability}

Code developed in Python3 and bash for this study is publicly available under an MIT license and can be found on GitHub [https://doi.org/10.5281/zenodo.4022248].

Received: 20 April 2020; Accepted: 23 September 2020;

Published online: 02 November 2020

\section{References}

1. Jacob, F. \& Monod, J. Genetic regulatory mechanisms in the synthesis of proteins. J. Mol. Biol. 3, 318-356 (1961).

2. Monod, J., Changeux, J. P. \& Jacob, F. Allosteric proteins and cellular control systems. J. Mol. Biol. 6, 306-329 (1963).

3. Wegner, A., Meiser, J., Weindl, D. \& Hiller, K. How metabolites modulate metabolic flux. Curr. Opin. Biotechnol. 34, 16-22 (2015).

4. Pardee, A. B. Regulatory molecular biology. Cell Cycle 5, 846-852 (2006)

5. Iommarini, L., Ghelli, A., Gasparre, G. \& Porcelli, A. M. Mitochondrial metabolism and energy sensing in tumor progression. Biochim. Biophys. Acta. Bioenerg. 1858, 582-590 (2017).

6. Schimke, R. T. \& Doyle, D. Control of enzyme levels in animal tissues. Annu. Rev. Biochem. 39, 929-976 (1970).

7. Welch, G. R. On the role of organized multienzyme systems in cellular metabolism: a general synthesis. Prog. Biophys. Mol. Biol. 32, 103-191 (1978).

8. de Graffenried, C. L. \& Bertozzi, C. R. The roles of enzyme localisation and complex formation in glycan assembly within the Golgi apparatus. Curr. Opin. Cell Biol. 16, 356-363 (2004).

9. Castellana, M. et al. Enzyme clustering accelerates processing of intermediates through metabolic channeling. Nat. Biotechnol. 32, 1011-1008 (2014).

10. Krebs, E. G. \& Beavo, J. A. Phosphorylation-dephosphorylation of enzymes. Ann. Rev. Biochem. 48, 923-959 (1979).

11. Zhao, S. et al. Regulation of cellular metabolism by protein lysine acetylation. Science 327, 1000-1004 (2010).

12. Monod, J., Wyman, J. \& Changeux, J. P. On the nature of allosteric transitions: a plausible model. J. Mol. Biol. 12, 88-118 (1965).

13. Koshland, D. E. Jr., Némethy, G. \& Filmer, D. Comparison of experimental binding data and theoretical models in proteins containing subunits. Biochemistry 5, 365-385 (1966).

14. Changeux, J. P. 50 years of allosteric interactions: The twists and turns of the models. Nat. Rev. Mol. Cell Biol. 14, 819-829 (2013).

15. Hilser, V. J., Anderson, J. A. \& Motlagh, H. N. Allostery vs. "allokairy”. Proc. Natl Acad. Sci. USA 112, 11430-11431 (2015).

16. Whittington, A. C. et al. Dual allosteric activation mechanism in monomeric human glucokinase. Proc. Natl Acad. Sci. USA 112, 11553-11558 (2015).

17. Neves, A. R., Pool, W. A., Kok, J., Kuipers, O. P. \& Santos, H. Overview on sugar metabolism and its control in Lactococcus lactis - the input from in vivo NMR. FEMS Microbiol. Rev. 29, 531-554 (2005).

18. Qian, N., Stanley, G. A., Hahn-Hägerdal, B. \& Rådström, P. Purification and characterization of two phosphoglucomutases from Lactococcus lactis subsp. lactis and their regulation in maltose- and glucose-utilizing cells. J. Bacteriol. 176, 5304-5311 (1994).

19. Qian, N., Stanley, G. A., Bunte, A. \& Rådström, P. Product formation and phosphoglucomutase activities in Lactococcus lactis: Cloning and characterization of a novel phosphoglucomutase gene. Microbiology 143, 855-865 (1997).
20. Andersson, U., Molenaar, D., Rådström, P. \& de Vos, W. M. Unity in organization and regulation of catabolic operons in Lactobacillus plantarum, Lactococcus lactis and Listeria monocytogenes. Syst. Appl. Microbiol. 28, 187-195 (2005).

21. Andersson, U., Levander, F. \& Rådström, P. Trehalose 6-phosphate phosphorylase is part of a novel metabolic pathway for trehalose utilization in Lactococcus lactis. J. Biol. Chem. 276, 42707-42713 (2001).

22. Sjöberg, A. \& Hahn-Hägerdal, B. $\beta$-Glucose 1-phosphate, a possible mediator for polysaccharide formation in maltose-assimilating Lactococcus lactis. Appl. Environ. Microbiol. 55, 1549-1554 (1989).

23. Levander, F., Andersson, U. \& Rådström, P. Physiological role of $\beta$ phosphoglucomutase in Lactococcus lactis. Appl. Environ. Microbiol. 67, 4546-4553 (2001).

24. Lahiri, S. D., Zhang, G., Rådström, P., Dunaway-Mariano, D. \& Allen, K. N. Crystallization and preliminary X-ray diffraction studies of $\beta$ phosphoglucomutase from Lactococcus lactis. Acta Cryst. D58, 324-326 (2002).

25. Zhang, G. et al. Catalytic cycling in $\beta$-phosphoglucomutase: a kinetic and structural analysis. Biochemistry 44, 9404-9416 (2005)

26. Baxter, N. J. et al. Trojan horse transition state analogue generated by $\mathrm{MgF}_{3}$ formation in an enzyme active site. Proc. Natl Acad. Sci. USA 103, 14732-14737 (2006)

27. Dai, J. et al. Analysis of the structural determinants underlying discrimination between substrate and solvent in $\beta$-phosphoglucomutase catalysis. Biochemistry 48, 1984-1995 (2009).

28. Goličnik, M. et al. Kinetic analysis of $\beta$-phosphoglucomutase and its inhibition by magnesium fluoride. J. Am. Chem. Soc. 131, 1575-1588 (2009).

29. Baxter, N. J. et al. Atomic details of near-transition state conformers for enzyme phosphoryl transfer revealed by $\mathrm{MgF}_{3}{ }^{-}$rather than by phosphoranes. Proc. Natl Acad. Sci. USA 107, 4555-4560 (2010).

30. Jin, Y. et al. $\alpha$-Fluorophosphonates reveal how a phosphomutase conserves transition state conformation over hexose recognition in its two-step reaction. Proc. Natl Acad. Sci. USA 111, 12384-12389 (2014).

31. Johnson, L. A. et al. van der Waals contact between nucleophile and transferring phosphorus is insufficient to achieve enzyme transition state architecture. ACS Catal. 8, 8140-8153 (2018).

32. Dai, J., Wang, L., Allen, K. N., Rådström, P. \& Dunaway-Mariano, D. Conformational cycling in $\beta$-phosphoglucomutase catalysis: Reorientation of the $\beta$-D-glucose 1,6-(bis)phosphate intermediate. Biochemistry 45, 7818-7824 (2006).

33. Wong, M., Khirich, G. \& Loria, J. P. What's in your buffer? Solute altered millisecond motions detected by solution NMR. Biochemistry 52, 6548-6558 (2013).

34. Gardner, K. H. \& Kay, L. E. The use of ${ }^{2} \mathrm{H},{ }^{13} \mathrm{C},{ }^{15} \mathrm{~N}$ multidimensional NMR to study the structure and dynamics of proteins. Annu. Rev. Biophys. Biomol. Struct. 27, 357-406 (1998).

35. Griffin, J. L. et al. Near attack conformers dominate $\beta$-phosphoglucomutase complexes where geometry and charge distribution reflect those of substrate. Proc. Natl Acad. Sci. USA 109, 6910-6915 (2012).

36. Shen, Y. \& Bax, A. Protein backbone and sidechain torsion angles predicted from NMR chemical shifts using artificial neural networks. J. Biomol. NMR 56, 227-241 (2013)

37. Goel, A., Santos, F., de Vos, W. M., Teusink, B. \& Molenaar, D. Standardized assay medium to measure Lactococcus lactis enzyme activities while mimicking intracellular conditions. Appl. Environ. Microbiol. 78, 134-143 (2012).

38. Zamberlin, Š., Antunac, N., Havranek, J. \& Samaržija, D. Mineral elements in milk and dairy products. Mljekarstvo 62, 111-125 (2012).

39. Grathwohl, C. \& Wüthrich, K. NMR studies of the rates of proline cis-trans isomerisation in oligopeptides. Biopolymers 20, 2623-2633 (1981).

40. Lu, K. P., Finn, G., Lee, T. H. \& Nicholson, L. K. Prolyl cis-trans isomerisation as a molecular timer. Nat. Chem. Biol. 3, 619-629 (2007).

41. Shen, Y. \& Bax, A. Prediction of Xaa-Pro peptide bond conformation from sequence and chemical shifts. J. Biomol. NMR 46, 199-204 (2010).

42. Cruz-Navarrete, F. A., Baxter, N. J., Wood, H. P., Hounslow, A. M. \& Waltho, J. P. ${ }^{1} \mathrm{H},{ }^{15} \mathrm{~N}$ and ${ }^{13} \mathrm{C}$ backbone resonance assignment of the $\mathrm{P} 146 \mathrm{~A}$ variant of $\beta$-phosphoglucomutase from Lactococcus lactis in its substrate-free form. Biomol. NMR Assign. 13, 349-356 (2019).

43. Klein, A. H., Shulla, A., Reimann, S. A., Keating, D. H. \& Wolfe, A. J. The intracellular concentration of acetyl phosphate in Escherichia coli is sufficient for direct phosphorylation of two-component response regulators. J. Bacteriol. 189, 5574-5581 (2007).

44. Bennett, B. D. et al. Absolute metabolic concentrations and implied enzyme active site occupancy in Escherichia coli. Nat. Chem. Biol. 5, 593-599 (2009).

45. Baxter, N. J. et al. Anionic charge is prioritized over geometry in aluminum and magnesium fluoride transition state analogs of phosphoryl transfer enzymes. J. Am. Chem. Soc. 130, 3952-3958 (2008). 
46. Odefey, C., Mayr, L. M. \& Schmid, F. X. Non-prolyl cis-trans peptide bond isomerisation as a rate-determining step in protein unfolding and refolding. J. Mol. Biol. 245, 69-78 (1995).

47. Cliff, M. J. et al. Transition state analogue structures of human phosphoglycerate kinase establish the importance of charge balance in catalysis. J. Am. Chem. Soc. 132, 6507-6516 (2010).

48. Jin, Y., Molt, R. W., Waltho, J. P., Richards, N. G. J. \& Blackburn, G. M. ${ }^{19} \mathrm{~F}$ NMR and DFT analysis reveal structural and electronic transition state features for RhoA-catalysed GTP hydrolysis. Angew. Chem. Int. Ed. 55 3318-3322 (2016).

49. Frieden, C. Slow transitions and hysteretic behavior in enzymes. Ann. Rev. Biochem. 48, 471-489 (1979).

50. Ricard, J., Meunier, J. C. \& Buc, J. Regulatory behavior of monomeric enzymes: the mnemonical enzyme concept. Eur. J. Biochem. 49, 195-208 (1974).

51. Ainslie, G. R., Shill, J. P. \& Neet, K. E. Transients and cooperativity: a slow transition model for relating transients and cooperative kinetics of enzymes. $J$. Biol. Chem. 247, 7088-7096 (1972).

52. Chae, Y. K. \& Markley, J. L. Functional recombinant rabbit muscle phosphoglucomutase from Escherichia coli. Protein Expr. Purif. 20, 124-127 (2000).

53. Zhang, C., Allen, K. N. \& Dunaway-Mariano, D. Mechanism of substrate recognition and catalysis of the haloalkanoic acid dehalogenase family member a-phosphoglucomutase. Biochemistry 57, 4504-4517 (2018).

54. Oesterhelt, C., Schnarrenberger, C. \& Gross, W. The reaction mechanism of phosphomannomutase in plants. FEBS Lett. 401, 35-37 (1997).

55. Reed, M. A. C. et al. Effects of domain dissection on the folding and stability of the $43 \mathrm{kDa}$ protein PGK probed by NMR. J. Mol. Biol. 330, 1189-1201 (2003).

56. Wood, H. P. et al. Enzymatic production of $\beta$-glucose 1,6-bisphosphate through manipulation of catalytic magnesium coordination. Preprint at https://doi.org/10.26434/chemrxiv.12982271.v2 (2020).

57. Hyberts, S. G., Robson, S. A. \& Wagner, G. Exploring signal-to-noise ratio and sensitivity in non-uniformly sampled multi-dimensional NMR spectra. J. Biomol. NMR 55, 167-178 (2013).

58. Hyberts, S. G., Milbradt, A. G., Wagner, A. B., Arthanari, H. \& Wagner, G. Application of iterative soft thresholding for fast reconstruction of NMR data non-uniformly sampled with multidimensional Poisson Gap scheduling. J. Biomol. NMR 52, 315-327 (2012).

59. Sun, Z. Y. J., Frueh, D. P., Selenko, P., Hoch, J. C. \& Wagner, G. Fast assignment of N-HSQC peaks using high-resolution $3 \mathrm{D}$ HNcocaNH experiments with non-uniform sampling. J. Biomol. NMR 33, 43-50 (2005)

60. Midelfort, C. F., Gupta, R. K. \& Rose, I. A. Fructose 1,6-bisphosphate: Isomeric composition, kinetics, and substrate specificity for the aldolases. Biochemistry 15, 2178-2185 (1976).

61. Winter, G. xia2: An expert system for macromolecular crystallography data reduction. J. Appl. Cryst. 43, 186-190 (2010).

62. Evans, P. R. \& Murshudov, G. N. How good are my data and what is the resolution? Acta Cryst. D69, 1204-1214 (2013).

63. Vagin, A. \& Teplyakov, A. MOLREP: an automated program for molecular replacement. J. Appl. Cryst. 30, 1022-1025 (1997).

64. Emsley, P., Lohkamp, B., Scott, W. G. \& Cowtan, K. Features and development of COOT. Acta Cryst. D66, 486-501 (2010).

65. Murshudov, G. N., Vagin, A. A. \& Dodson, E. J. Refinement of macromolecular structures by the maximum-likelihood method. Acta Cryst. D53, 240-255 (1997).

66. Chen, V. B. et al. MolProbity: All-atom structure validation for macromolecular crystallography. Acta Cryst. D66, 12-21 (2010).
67. McNicholas, S., Potterton, E., Wilson, K. S. \& Noble, M. E. M. Presenting your structures: the CCP4mg molecular-graphics software. Acta Cryst. D67, 386-394 (2011).

\section{Acknowledgements}

We thank Dr Claudine Bisson for helpful discussions and interpretation of X-ray crystallography data. We thank the beamline scientists at the DLS for the provision of synchrotron radiation facilities and assistance with data collection. This research was supported by the Biotechnology and Biological Sciences Research Council (BBSRC; H.P.W.-Grant Number X/009906-20-26, N.J.B.-Grant Number BB/M021637/1 and BB/S007965/1, C.R.T.—Grant Number BB/P007066/1), Consejo Nacional de Ciencia y Tecnologia, Mexico (CONACYT; F.A.C.N.-Grant Number 472448) and The Royal Society (S.R.D.-Grant Number R/152968).

\section{Author contributions}

H.P.W., F.A.C.N., N.J.B., C.R.T., A.J.R., J.P.W. designed research; H.P.W., F.A.C.N., C.R.T., A.J.R. produced isotopically enriched protein; H.P.W. performed coupled assay kinetic experiments; H.P.W., C.R.T. produced and purified $\beta$ G1P and $\beta$ G16BP; H.P.W., F.A.C.N., C.R.T., A.M.H., M.J.C. acquired NMR experiments; H.P.W., F.A.C.N., N.J.B. C.R.T. analysed NMR data; F.A.C.N., N.J.B., C.R.T. performed backbone resonance assignments; H.P.W., A.J.R., S.R.D. performed and analysed X-ray crystallography experiments; F.A.C.N. conceived and developed the allomorphy mechanism; H.P.W., F.A.C.N., N.J.B., C.R.T., J.P.W. wrote the paper with help from all authors.

\section{Competing interests}

The authors declare no competing interest.

\section{Additional information}

Supplementary information is available for this paper at https://doi.org/10.1038/s41467 020-19215-9.

Correspondence and requests for materials should be addressed to F.A.C.N. or J.P.W.

Peer review information Nature Communications thanks Andrea Mattevi and other, anonymous, reviewers for their contributions to the peer review reports of this work. Peer review reports are available.

Reprints and permission information is available at http://www.nature.com/reprints

Publisher's note Springer Nature remains neutral with regard to jurisdictional claims in published maps and institutional affiliations.

Open Access This article is licensed under a Creative Commons Attribution 4.0 International License, which permits use, sharing, adaptation, distribution and reproduction in any medium or format, as long as you give appropriate credit to the original author(s) and the source, provide a link to the Creative Commons license, and indicate if changes were made. The images or other third party material in this article are included in the article's Creative Commons license, unless indicated otherwise in a credit line to the material. If material is not included in the article's Creative Commons license and your intended use is not permitted by statutory regulation or exceeds the permitted use, you will need to obtain permission directly from the copyright holder. To view a copy of this license, visit http://creativecommons.org/ licenses/by/4.0/

(C) The Author(s) 2020 